M-2363

J. Chem. Thermodynamics 1989, 21, 631-651

\title{
Heat capacity, thermodynamic properties, and transitions of silver iodide $^{a}$
}

\author{
ROEY SHAVIV, EDGAR F. WESTRUM, JR., \\ Department of Chemistry, University of Michigan, \\ Ann Arbor, MI 48109, U.S.A. \\ FREDRIK GRØNVOLD, SVEIN STØLEN, \\ Department of Chemistry, University of Oslo. \\ Blindern, Box 1033,0315 Oslo 3. Norway
}

\begin{abstract}
AKIRA INABA, HITOSHI FUJII, and HIDEAKI CHIHARA
Department of Chemistry and Chemical Thermodynamics Laboratory, Faculty of Science, Osaka University, Toyonaka, Osaka 560, Japan
\end{abstract}

(Received 6 February 1989)

\begin{abstract}
The heat capacity of silver iodide was measured using adiabatic calorimetric cryostats over the ranges 7 to $350 \mathrm{~K}$ and from 2 to $75 \mathrm{~K}$. The $(\beta$ to $\alpha)$ - and $(\beta / \gamma$ to $\alpha)$-transitions and the heat capacities of single crystals of $\beta$, of finely divided $\beta / \gamma$-, and of the $\alpha$-phases were measured in adiabatic calorimetric cryostats and thermostats from 70 to $700 \mathrm{~K}$ and from 310 to $523 \mathrm{~K}$. The values of $C_{p, \mathrm{~m}}, S_{\mathrm{m}}^{\circ}$, and $\Phi_{\mathrm{m}}^{\circ}$ at $298.15 \mathrm{~K}$ are $6.707 R, 13.764 R$, and $8.511 R$ for the $\beta$-phase and since the molar volumes of $\beta$ - and $\gamma$-phases are identical and the structures differ only in their stacking sequence, their heat capacities are essentially identical. Moreover, the molar transition-enthalpy increments to the $\alpha$-phase of the two samples are also equal within the accuracy of the present measurements in spite of the structural differences occasioned by the presence of some $\gamma-\mathrm{AgI}$ in one of them (below the transition temperature). The (partial) enthalpy of the $(\beta / \gamma$ to $\alpha)$-phase transition was found to be $(758.7 \pm 0.8) R \cdot \mathrm{K}$ and that of the $(\beta$ to $\alpha$ )-phase transition was found to be $(758.0 \pm 0.3) R \cdot K$ over the range 405 to $425 \mathrm{~K}$ imean: $(758.4 \pm 0.4) R \cdot \mathbf{K}\}$. The (total) enthalpy of transition is about $1150 R \cdot \mathbf{K}$. An abnormal trend in the heat capacity in the low-temperature region was noted. The heat-capacity values are compared with those of prior overlapping measurements by Nernst and Schwers, by Pitzer, and by Madison et al. for the $\beta / \gamma$-phase, and in and beyond the transition region with those of numerous prior investigators.
\end{abstract}

\section{Introduction}

The polytypes of silver iodide ${ }^{(1)}$ at ambient atmospheric conditions are a hexagonal wurtzite-type structure $(\boldsymbol{\beta}-\mathrm{AgI})$ coexisting with a cubic face-centered sphalerite-type modification $\left(\gamma\right.$-AgI); ${ }^{(2)}$ however, only the former is thermodynamically stable below $420 \mathrm{~K}$. The conversion rate for the metastable phase is measurable only above $390 \mathrm{~K}$, and the transition does not easily go to completion. ${ }^{(3)}$ At $420 \mathrm{~K}$ a first-order phase

"Contribution No. 131 from the Chemical Thermodynamics Laboratory, Osaka University. 
transition yields a body-centered cubic modification $(\alpha-\mathrm{AgI})^{(4)}$ with high ionic mobility and consequent high (ionic) electric conductivity approaching that of a liquid electrolyte. ${ }^{(5)}$

Numerous reports on the heat capacity of silver iodide by adiabatic calorimetry near the disordering phase transition are extant ${ }^{\left(6^{16)}\right.}$ as are $\Delta_{\mathrm{trs}} H$ determinations by other methods.

The first heat-capacity determination of $\beta / \gamma$-silver iodide (from 18 to $116 \mathrm{~K}$ ) is among the very early measurements of Nernst and Schwers ${ }^{(17)}$ and a second-of more recent vintage - from 15 to $300 \mathrm{~K}$ by Pitzer. ${ }^{(18)}$ The low end (from 1.8 to $20 \mathrm{~K}$ ) of the heat capacity was measured more recently by Madison et al. ${ }^{(19)}$ In these studies, the temperature dependence at low temperatures was claimed to be at variance with Debye-like trends. These results are confirmed by the present work and are discussed later in this text.

Subsequently Pcrrott and Fletcher ${ }^{(6}{ }^{10)}$ observed different heat capacities for samples of different stoichiometry. They found a much higher heat capacity for the stoichiometric $\alpha-\mathrm{AgI}$ than for the non-stoichiometric $\alpha$-AgI over the region 430 to $800 \mathrm{~K}$ and an ordering transition with $\Delta_{\mathrm{trs}} H_{\mathrm{m}}^{\circ}=(151 \pm 25) R \cdot \mathrm{K}$ near $700 \mathrm{~K}$. Their results were contradicted by Jost ${ }^{(11)}$ as well as by Nölting and Rein. ${ }^{(16)}$ Perrott and Fletcher found similar phenomena in the heat capacity of silver sulfide. ${ }^{(20)}$ But more recently Grønvold and Westrum ${ }^{(21)}$ _after independent measurements - found no evidence in support of Perrott and Fletcher's observations and hence of their model for disorder. Okazaki and Takano concur. ${ }^{(22)}$

There are, however, several experimental indications of the onset of an order/ disorder phenomenon on the $\mathrm{Ag}^{+}$cation sublattice in $\mathrm{AgI}(675$ to $700 \mathrm{~K})$ involving a change in the activation energy for the ionic conductivity noted by Allen and Lazarus, ${ }^{(23)}$ and by Fontana et al., ${ }^{(24)}$ together with a decrease in the $\alpha$-AgI integrated Raman intensity reported by Mariotto et al. ${ }^{(25)}$ The same phenomenon is confirmed in molecular-dynamics simulation studies by Tallon, ${ }^{(26)}$ and even more recently in Brillouin spectra across this region by Börjesson and Torell, ${ }^{(27)}$ revealing changes in the trend of the temperature dependence of the longitudinal and transverse modes as well as in the phonon propagation near the predicted transition temperature. These effects are typical of the Brillouin component on passage through a glass transition. Of the many models used to interpret the intriguing experimental results, a typical one ${ }^{(28)}$ neither implies the existence nor does it exclude the possibility of such a temperature at which the "percolation" in the iodine cage system would be broken. The essential linearity of Lawn' ${ }^{(29)} X$-ray determined density of the $\alpha$-phase from 423 to $720 \mathrm{~K}$ precludes the presence of a transition.

The temperature-dependent cooperative correlation between occupied silver sites deduced from Raman spectra of Mazzacurati et al. ${ }^{(28)}$ was supported through the lattice-gas calculations by $\mathrm{Szabo}^{(30)}$ which pointed to the existence of an intermediate partially ordered phase. Further calculations by Szabo and Kertész ${ }^{(31)}$ showed that the self diffusion is strongly anisotropic in the intermediate phase as well as in the ordered low-temperature one.

To resolve all these ambiguities the present authors (on three continents) prepared two distinct samples of silver iodide - one finely divided material a $(\beta / \gamma$-mixture $)$ and 
the other a single crystal $\beta$-sample - and characterized these by X-ray diffraction and studied their heat capacities, the former from 7 to $350 \mathrm{~K}$ (Ann Arbor) and from 310 to $523 \mathrm{~K}$ (Oslo) and the latter from ( 2 to $75 \mathrm{~K}$ ) and from ( 70 to $700 \mathrm{~K}$ ) (both at Osaka). Hence four calorimeters and two samples were employed.

\section{Experimental}

\section{SAMPLE PROVENANCE AND CHARACTERIZATION}

The Oslo sample was made by reacting stoichiometric quantities of $99.99+$ mass per cent metallic silver (American Smelting \& Refining Co.) and 99.998 mass per cent iodine flakes (Koch-Light Laboraties) in evacuated sealed silica-glass tubes. The yellow powder formed was first heat treated at $370 \mathrm{~K}$ for $1 \mathrm{~d}$, and subsequently for $1 \mathrm{~d}$ at $410 \mathrm{~K}, 11 \mathrm{~d}$ at $470 \mathrm{~K}, 1 \mathrm{~d}$ at $520 \mathrm{~K}, 1 \mathrm{~d}$ at $570 \mathrm{~K}$, and $11 \mathrm{~d}$ at $670 \mathrm{~K}$, before being cooled within the furnace to room temperature.

To get the purest possible $\beta$-phase, the Osaka University sample consisted of selected single crystals. Since silver iodide has always proved difficult to grow from solution, a gel method was applied. ${ }^{(32)}$ The process involves diffusion of $\mathrm{AgI}-\mathrm{HI}$ complexcs in solution into an acidic (HI) gel, and the subsequent dissociation of the complex with increasing dilution. The procedures which followed precipitation of fine silver iodide powder from $\mathrm{AgNO}_{3}$ and $\mathrm{HI}$ solutions are described elsewhere. ${ }^{(33)}$ The crystals in the gel appeared to be completely clear small hexagonal pyramids up to $3 \mathrm{~mm}$ in base diameter, from which the crystals larger than $0.5 \mathrm{~mm}$ in size were loaded into the calorimeter vessel. The reagents used were purchased from Wako Pure Chemical Industries, Ltd. The Gel-grown crystals thus obtained are of highpurity stoichiometric $\beta$-AgI single crystals without inclusions. ${ }^{(33)}$

Powder X-ray diffraction photographs at room temperature were taken in an $80 \mathrm{~mm}$ diameter Guinier camera with $\mathrm{Cu} \mathrm{K} \alpha_{1}$ radiation and silicon as calibration substance; $a(293 \mathrm{~K})=543.1065 \mathrm{pm}$ for $\mathrm{Si}^{\left({ }^{(34)}\right.}$ Unit-cell dimensions to characterize the samples were derived by the method of least squares using the program CELLKANT. ${ }^{(35)}$

The Oslo sample consists of a mixture of $\beta$ - and $\gamma$-AgI with cell constants $a=(459.36 \pm 0.07) \mathrm{pm}$ and $c=(751.3 \pm 0.2) \mathrm{pm}, \quad$ and $a=(649.9 \pm 0.6) \mathrm{pm}$, respectively. $\uparrow$ The very weak cubic 331 reflection is the only definite proof of the presence of $\gamma-\mathrm{AgI}$ in the Oslo sample; see table 1 . The three strong reflections 111 , 220 , and 311 overlap with the hexagonal 002,110 , and 112 reflections, respectively. Thus, the hexagonal close packing of the iodine atoms is close to ideal $\{c / a=$ $\left.1.6356 \approx(8 / 3)^{1 / 2}\right\}$ and the molar volumes of the two close-packed structures $\left(a_{\text {sub }} / a_{\text {hex }}=1.414 \approx \sqrt{2}\right)$ are equal within the limits of error for ideal stoichiometry.

The Osaka sample, even after heating to $700 \mathrm{~K}$ and cooling to $2 \mathrm{~K}$, shows the presence of only hexagonal $\beta$-AgI with lattice constants: $a=(459.16 \pm 0.05) \mathrm{pm}$. $\therefore=(750.98 \pm 0.20) \mathrm{pm} . \dagger$

The unit cell dimensions obtained agree well with results by Burley ${ }^{(36)}$ a $a=$ $1459.2 \pm 0.4) \mathrm{pm}, c=(751.0 \pm 0.4) \mathrm{pm}\}$, by Chateau et al. ${ }^{(37)}\{a=(459.24 \pm 0.02) \mathrm{pm}$.

\footnotetext{
† The uncertainties given for the present results indicate one standard deviation.
} 
TABLE 1. X-ray powder results for the Osaka and the Oslo calorimetric samples of silver iodide, together with calculated $(\sin \theta)^{2}$ and intensity values of the reflections from the hexagonal and cubic polytypes ( $\mathrm{Cu} \mathrm{K} \alpha_{1}$ radiation)

\begin{tabular}{cccccccccc}
\hline \multicolumn{2}{c}{ AgI (Osaka) } & \multicolumn{2}{c}{ AgI (Oslo) } & \multicolumn{3}{c}{$\beta$-AgI (hexagonal) } & \multicolumn{2}{c}{$\gamma$-AgI (cubic) } \\
$10^{5}(\sin \theta)^{2}$ & $I$ & $10^{5}(\sin \theta)^{2}$ & $I$ & $h k l$ & $10^{5}(\sin \theta)^{2}$ & $I$ & $h k l$ & $10^{5}(\sin \theta)^{2}$ & $I$ \\
\hline 3759 & 1000 & 3741 & 305 & 100 & 3750 & 1000 & & & \\
4213 & 790 & 4200 & 241 & 002 & 4201 & 571 & 111 & 4215 & 1000 \\
4806 & 516 & 4801 & 164 & 101 & 4805 & 652 & & & \\
- & - & - & - & & & & 200 & 5619 & 3 \\
7961 & 226 & 7955 & 84 & 102 & 7955 & 343 & & & \\
11259 & 981 & 11259 & 1000 & 110 & 11248 & 792 & 220 & 11239 & 761 \\
13217 & 543 & 13216 & 155 & 103 & 13211 & 781 & & & \\
15012 & 137 & 15008 & 85 & 200 & 14997 & 122 & & & \\
15468 & 555 & 15466 & 552 & 112 & 15453 & 465 & 311 & 15453 & 470 \\
16091 & $a$ & 16095 & $a$ & 201 & 16048 & 103 & & & \\
- & - & - & - & 004 & 16821 & 2 & 222 & 16858 & 1 \\
19199 & 55 & 19190 & 20 & 202 & 19202 & 76 & & & \\
- & - & - & - & 104 & 20570 & 2 & & & \\
- & - & - & - & & & & & & \\
24486 & 128 & 24459 & 72 & 203 & 24459 & 261 & & & \\
26270 & 90 & 26232 & 37 & 210 & 26245 & 89 & & & \\
- & - & 26677 & 10 & & & & 331 & 26692 & 203 \\
\hline
\end{tabular}

${ }^{a}$ Coincides with Si-reflection.

$c=751.04 \mathrm{pm}\}$ and by Wilman ${ }^{(38)}\{a=(459.2 \pm 0.2) \mathrm{pm}, c=(753.6 \pm 0.2) \mathrm{pm}\}$ for $\beta$-AgI and by Burley ${ }^{(39)}\{a=(648.9 \pm 0.5) \mathrm{pm}\}$, by Wilman ${ }^{(38)}\{a=(648.9 \pm 0.5) \mathrm{pm}\}$ and by Berry ${ }^{(40)}\{a=(649 \pm 2) \mathrm{pm}\}$ for $\gamma$-AgI.

In an attempt to determine the relative amounts of $\beta$ - and $\gamma-\mathrm{AgI}$ in the Oslo sample, intensities of the reflections on the Guinier photographs were calculated by the program LAZY-PULVERIX ${ }^{(41)}$ For the hexagonal structure the coordinates and isotropic temperature factors derived by Burley ${ }^{(36)}$ were used. The results are given in table 1 . The agreement between observed intensities for presumably pure $\beta$-AgI (Osaka) and those calculated is fair. According to Burley, ${ }^{(36)}$ the displacement model with the silver atoms in the tetrahedral-bond directions is not supported by the experimental results. Further attempts by Burley ${ }^{(36)}$ to improve the agreement between his observed and calculated structure factors and corrections for anomalous dispersion, led only to a slight improvement of the $R$-factor from 8.0 to 6.6 per cent. A more recent refinement attempt by Cava et al ${ }^{(42)}$ by neutron diffraction did not bring the $R$-factor below 6.5 per cent. The lack of agreement was ascribed in part to inadequacy of the extinction correction used.

In the present intensity calculations for cubic $\gamma$-AgI, the sphalerite or zinc-blende type structure was assumed. The results show that the 331 reflection should have considerable intensity. It is, however, very weak in the Oslo sample, and indicates that $\beta$-AgI dominates. Superposed reflections from $\beta$ - and $\gamma$-AgI with their calculated intensities do not yield the intensities observed for the Oslo sample. Whether this is occasioned by incorrect structural models, preferred orientation, anomalous absorption, or other phenomena is not yet known. Crushing the Osaka crystals does, 
however, lead to intensity relations similar to those reported for the Oslo sample in table 1 . Furthermore, the intensity relation in the Oslo sample was found to vary somewhat with heat treatment.

\section{CALORIMETRIC TECHNIQUE}

The cryogenic heat-capacity measurements at Ann Arbor were made in the Mark X adiabatic cryostat, which has been described previously. ${ }^{(43)}$ The sample was contained in a gold-plated copper calorimeter (laboratory designation W-139). The calorimeter had a mass of $13.21 \mathrm{~g}$ and an internal volume of $23 \mathrm{~cm}^{3}$. The temperature of the calorimeter was measured with a Leeds \& Northrup platinum-encapsulated resistance thermometer in an entrant well. The thermometer was calibrated by the U.S. National Bureau of Standards against IPTS-68 and is considered to reproduce the thermodynamic temperature scale within $0.03 \mathrm{~K}$ from 5 to $300 \mathrm{~K}$.

About $71.9 \mathrm{~g}$ of sample were put into the calorimeter. This corresponds to about $0.3 \mathrm{~mol} ; 234.7727 \mathrm{~g} \cdot \mathrm{mol}^{-1}$ was selected as the molar mass of AgI. To facilitate rapid thermal equilibration $2.03 \mathrm{kPa}$ at $300 \mathrm{~K}$ of helium gas was introduced after evacuation. The calorimeter was then sealed, placed in the cryostat, and cooled. The heat capacity of the empty calorimeter represented 10 per cent of the total heat capacity at temperatures below $50 \mathrm{~K}$ and became about 25 to 30 per cent at higher temperatures.

The heat-capacity measurements at Osaka University were made with two adiabatic calorimeters; one was employed for measurements between 2 and $75 \mathrm{~K}$ and the other between 70 and $700 \mathrm{~K}$. Although both have been described already, ${ }^{(44.45)}$ new calorimetric vessels were used and will be described elsewhere. ${ }^{(46)}$ The IPTS-68 temperature scale was used for two platinum resistance thermometers above $13.81 \mathrm{~K}$ and the helium vapor-pressure scale and a gas-thermometric scale were used for a germanium resistance thermometer below $15 \mathrm{~K}$. The mass of the sample loaded was $17.6 \mathrm{~g}$ for both measurements. The heat capacity of the empty calorimeter in the Osaka experiment, represented 35 per cent at $3 \mathrm{~K}$ decreasing to 11 per cent at $10 \mathrm{~K}$ and gradually increasing from 26 to 70 per cent of the total heat capacity between 20 and $70 \mathrm{~K}$ for the low-temperature cryostat. For the high-temperature cryostat at Osaka the heat capacity of the empty calorimeter was between 63 per cent and 74 per cent over the entire temperature range of the experiment $(70$ to $700 \mathrm{~K}$ ).

The high-temperature calorimetric apparatus and measuring technique at Oslo have already been described in detail. ${ }^{(47)}$ The computer-operated calorimeter was intermittently heated and was surrounded by clectrically heated and clectronically controlled adiabatic shields. The sample was enclosed in an evacuated and sealed silica-glass tube of about $50 \mathrm{~cm}^{3}$ volume, tightly fitted into the silver calorimeter. A central entrant well in the tube served for the heater and platinum resistance thermometer. The resistance-thermometer was calibrated locally, at the ice, steam, tin, and zinc points. Temperatures are judged to correspond with IPTS-68 to within $0.08 \mathrm{~K}$.

The heat capacity of the empty calorimeter was determined in a separate series of experiments and was about 45 per cent of the total with a standard deviation of a 
TABLE 2. Molar heat capacities of silver iodide $\left(R=8.3144 \mathrm{~J} \cdot \mathrm{K}^{-1} \cdot \mathrm{mol}{ }^{\prime} ; M(\mathrm{Agl})=234.7727 \mathrm{~g} \cdot \mathrm{mol}{ }^{1}\right)$

\begin{tabular}{|c|c|c|c|c|c|c|c|c|c|}
\hline$T / \mathbf{K}$ & $C_{p, \mathrm{~m}} / R$ & $T / \mathrm{K}$ & $C_{m, \mathrm{~m}} / R$ & $T / \mathrm{K}$ & $C_{p, \mathrm{~m}} / R$ & $T / \mathrm{K}$ & $C_{p, \mathbf{m} /} / R$ & $T / \mathbf{K}$ & $C_{p, \mathrm{~m}} / R$ \\
\hline \multicolumn{10}{|c|}{ Low-temperature measurements-University of Michigan } \\
\hline \multicolumn{2}{|c|}{ Series I } & 138.91 & 5.836 & 257.79 & 6.480 & 9.06 & 0.794 & 37.75 & 3.168 \\
\hline 282.48 & 6.613 & 144.03 & 5.878 & 262.97 & 6.506 & 9.95 & 0.912 & 39.62 & 3.299 \\
\hline 289.04 & 6.653 & 149.16 & 5.915 & 268.15 & 6.533 & 10.86 & 1.023 & 41.58 & 3.432 \\
\hline 295.57 & 6.684 & 154.31 & 5.949 & 273.33 & 6.559 & 11.80 & 1.125 & 43.64 & 3.565 \\
\hline 302,09 & 6.725 & 159.48 & 5.984 & 278.51 & 6.588 & 12.75 & 1.220 & 45.80 & $3: 701$ \\
\hline 308.61 & 6.765 & 164.64 & 6.016 & 283.69 & 6.622 & 13.71 & 1.311 & 48.08 & 3.835 \\
\hline 315.13 & 6.804 & 169.80 & 6.045 & 288.87 & 6.652 & 14.67 & 1.404 & 50.47 & 3.968 \\
\hline 321.65 & 6.843 & 174.97 & 6.074 & 294.06 & 6.677 & 15.65 & 1.487 & 55.38 & 4.215 \\
\hline 328.17 & 6.885 & 180.14 & 6.101 & 299.24 & 6.706 & 16.73 & 1.572 & 58.29 & 4.349 \\
\hline 334.68 & 6.931 & 185.31 & 6.126 & & & 17.90 & 1.660 & 61.29 & 4.476 \\
\hline 341.20 & 6.981 & 190.48 & 6.152 & Serie & s III & 19.08 & 1.747 & 64.79 & 4.608 \\
\hline \multirow[t]{2}{*}{346.54} & 7.014 & 195.65 & 6.178 & 8.79 & 0.755 & 20.34 & 1.841 & 68.78 & 4.737 \\
\hline & & 200.83 & 6.202 & 9.74 & 0.885 & 21.73 & 1.942 & 72.79 & 4.853 \\
\hline \multicolumn{2}{|c|}{ Series II } & 206.00 & 6.226 & 10.64 & 0.998 & 23.10 & 2.046 & 76.81 & 4.965 \\
\hline 93.73 & 5.326 & 211.18 & 6.250 & 11.57 & 1.100 & 24.47 & 2.150 & 80.84 & 5.075 \\
\hline 98.71 & 5.393 & 216.36 & 6.275 & 12.52 & 1.198 & 25.78 & 2.249 & 85.37 & 5.187 \\
\hline 103.59 & 5.461 & 221.53 & 6.300 & 13.47 & 1.289 & 27.06 & 2.347 & 90.42 & 5.279 \\
\hline 108.40 & 5.527 & 226.71 & 6.325 & 14.44 & 1.383 & 28.40 & 2.450 & 95.50 & 5.349 \\
\hline 113.34 & 5.594 & 231.89 & 6.350 & 15.41 & 1.469 & 29.80 & 2.558 & 100.58 & 5.420 \\
\hline 118.45 & 5.651 & 237.07 & 6.376 & & & 31.27 & 2.674 & 105.67 & 5.493 \\
\hline 123.57 & 5.703 & 242.25 & 6.402 & Serie & S IV & 32.74 & 2.789 & 110.76 & 5.559 \\
\hline 128.70 & 5.747 & 247.43 & 6.427 & 7.41 & 0.536 & 34.29 & 2.909 & 116.12 & 5.626 \\
\hline 133.80 & 5.794 & 252.61 & 6.452 & 8.20 & 0.667 & 35.98 & 3.038 & & \\
\hline \multicolumn{10}{|c|}{ High-temperature measurements - University of Oslo } \\
\hline \multicolumn{2}{|c|}{ Series V } & 489.72 & 6.882 & $\Delta_{\mathrm{trs}} H_{\mathrm{m}}$ & Detn. B & Serie & s VII & 453.05 & 6.890 \\
\hline 374.06 & 7.208 & 498.39 & 6.878 & 422.88 & 6.938 & 326.15 & 6.850 & 458.61 & 6.890 \\
\hline 382.39 & 7.310 & 507.07 & 6.866 & 430.10 & 6.926 & 338.59 & 6.942 & 464.19 & 6.882 \\
\hline 390.67 & 7.392 & & & 438.63 & 6.930 & 350.98 & 7.028 & 469.78 & 6.858 \\
\hline 398.92 & 7.514 & \multicolumn{2}{|c|}{ Series VI } & 450.50 & 6.920 & 363.28 & 7.140 & 475.39 & 6.870 \\
\hline$\Delta_{\mathrm{trs}} H_{\mathrm{m}}$ & Detn. A & 315.20 & 6.806 & 462.44 & 6.908 & 375.51 & 7.260 & 484.44 & 6.872 \\
\hline 429.57 & 6.920 & 327.05 & 6.868 & 474.46 & 6.882 & 387.67 & 7.392 & 497.10 & 6.862 \\
\hline 438.11 & 6.916 & 338.84 & 6.944 & 486.56 & 6.858 & 399.37 & 7.558 & 509.83 & 6.838 \\
\hline 446.67 & 6.922 & 350.59 & 7.034 & 498.77 & 6.830 & $\Delta_{\mathrm{trs}} H_{\mathrm{m}}$ & Detn. C & 522.61 & 6.848 \\
\hline 455.24 & 6.904 & 362.29 & 7.140 & 510.90 & 6.844 & 430.76 & 6.896 & & \\
\hline 463.83 & 6.892 & 373.83 & 7.260 & 523.04 & 6.818 & 436.35 & 6.904 & & \\
\hline 472.45 & 6.884 & 385.36 & 7.328 & & & 441.92 & 6.902 & & \\
\hline 481.08 & 6.894 & 396.87 & 7.438 & & & 447.49 & 6.892 & & \\
\hline \multicolumn{10}{|c|}{ High-temperature measurements--Osaka University } \\
\hline \multicolumn{2}{|c|}{ Series I } & 90.894 & 5.274 & 116.926 & 5.619 & 144.868 & 5.863 & 173.839 & 6.041 \\
\hline 69.645 & 4.760 & 92.915 & 5.308 & 119.213 & 5.642 & 147.200 & 5.881 & 176.339 & 6.057 \\
\hline 71.522 & 4.815 & 94.963 & 5.338 & 121.511 & 5.665 & 149.549 & 5.899 & 178.845 & 6.068 \\
\hline 73.385 & 4.871 & 97.041 & 5.362 & 123.823 & 5.687 & 151.914 & 5.910 & 181.374 & 6.083 \\
\hline 75.254 & 4.920 & 99.148 & 5.392 & 126.159 & 5.711 & 154.286 & 5.926 & 183.912 & 6.097 \\
\hline 77.142 & 4.967 & 101.283 & 5.426 & 128.494 & 5.730 & 156.670 & 5.938 & 186.457 & 6.111 \\
\hline 79.050 & 5.023 & 103.445 & 5.454 & 130.842 & 5.751 & 159.071 & 5.955 & 189.010 & 6.124 \\
\hline 80.980 & 5.082 & 105.637 & 5.483 & 133.189 & 5.771 & 161.492 & 5.967 & 191.562 & 6.140 \\
\hline 82.931 & 5.126 & 107.866 & 5.516 & 135.521 & 5.791 & 163.933 & 5.984 & 194.120 & 6.153 \\
\hline 84.904 & 5.169 & 110.118 & 5.541 & 137.852 & 5.810 & 166.397 & 5.998 & 196.679 & 6.166 \\
\hline 86.902 & 5.210 & 112.379 & 5.570 & 140.195 & 5.828 & 168.868 & 6.012 & 199.241 & 6.181 \\
\hline 88.899 & 5.244 & 114.648 & 5.595 & 142.538 & 5.849 & 171.343 & 6.027 & 201.812 & 6.193 \\
\hline
\end{tabular}


TABLE 2--continued

\begin{tabular}{|c|c|c|c|c|c|c|c|c|c|}
\hline$T / \mathrm{K}$ & $C_{p, \mathrm{~m}} / R$ & $T / \mathbf{K}$ & $C_{p, \mathrm{~m}} / R$ & $T / \mathbf{K}$ & $C_{p, \mathrm{~m}} / R$ & $T / \mathbf{K}$ & $C_{p, \mathrm{~m}} / R$ & $T / \mathrm{K}$ & $C_{p, \mathrm{~m} /} R$ \\
\hline 204.389 & 6.206 & 303.780 & 6.749 & $\Delta_{\mathrm{trs}} H_{\mathrm{m}}$ & Detn. $A^{\prime}$ & 484.033 & 6.871 & 617.936 & 6.792 \\
\hline 206.976 & 6.222 & 306.631 & 6.770 & 425.637 & 6.967 & 487.498 & 6.862 & 621.589 & 6.791 \\
\hline 209.603 & 6.234 & 309.479 & 6.789 & 428.787 & 6.954 & 491.269 & 6.865 & 625.235 & 6.804 \\
\hline 212.209 & 6.246 & 312.331 & 6.806 & 431.263 & 6.942 & 494.766 & 6.863 & 628.879 & 6.786 \\
\hline 214.825 & 6.259 & 315.176 & 6.828 & 433.946 & 6.937 & 498.277 & 6.857 & 632.515 & 6.794 \\
\hline 217.443 & 6.275 & 318.028 & 6.845 & 436.958 & 6.927 & 501.808 & 6.858 & 636.150 & 6.799 \\
\hline 220.054 & 6.283 & 320.886 & 6.863 & 440.021 & 6.919 & 505.375 & 6.858 & 639.821 & 6.794 \\
\hline 222.668 & 6.298 & 323.744 & 6.880 & 443.141 & 6.912 & 508.982 & 6.854 & 643.458 & 6.801 \\
\hline 325.311 & 6.312 & 326.604 & 6.904 & 446.265 & 6.918 & 512.631 & 6.854 & 647.080 & 6.804 \\
\hline 227.987 & 6.322 & 329.468 & 6.924 & 449.393 & 6.904 & 516.335 & 6.846 & 650.704 & 6.785 \\
\hline 230.679 & 6.337 & 332.337 & 6.946 & 452.526 & 6.904 & 520.091 & 6.839 & 654.325 & 6.792 \\
\hline 233.399 & 6.352 & 335.206 & 6.958 & 455.672 & 6.900 & 523.890 & 6.829 & 657.941 & 6.812 \\
\hline 236.153 & 6.366 & 338.076 & 6.978 & 458.831 & 6.899 & 527.726 & 6.828 & 661.554 & 6.799 \\
\hline 238.978 & 6.388 & 340.940 & 7.006 & 462.002 & 6.899 & 531.598 & 6.826 & 665.159 & 6.813 \\
\hline 241.760 & 6.400 & 343.799 & 7.026 & 465.188 & 6.894 & 535.514 & 6.821 & 668.764 & 6.812 \\
\hline 244.553 & 6.414 & 346.663 & 7.049 & & & 539.448 & 6.818 & 672.367 & 6.812 \\
\hline 247.348 & 6.426 & 349.533 & 7.076 & Seri & ies II & 543.612 & 6.822 & 675.965 & 6.813 \\
\hline 250.145 & 6.442 & 352.405 & 7.097 & 422.635 & 6.919 & 547.599 & 6.816 & 679.557 & 6.835 \\
\hline 252.944 & 6.453 & 355.280 & 7.123 & 425.666 & 6.918 & 551.622 & 6.810 & 683.148 & 6.826 \\
\hline 255.737 & 6.467 & 358.150 & 7.145 & 428.713 & 6.917 & 555.681 & 6.806 & 686.742 & 6.845 \\
\hline 258.533 & 6.484 & 361.025 & 7.167 & 431.786 & 6.922 & 559.781 & 6.809 & 690.321 & 6.838 \\
\hline 261.331 & 6.495 & 363.905 & 7.186 & 434.887 & 6.913 & 563.920 & 6.810 & 693.902 & 6.838 \\
\hline 264.139 & 6.508 & 366.780 & 7.219 & 438.022 & 6.918 & 568.094 & 6.811 & 697.488 & 6.835 \\
\hline 266.958 & 6.525 & 369.657 & 7.242 & 441.193 & 6.917 & 570.247 & 6.811 & 701.070 & 6.860 \\
\hline 269.781 & 6.546 & 372.538 & 7.269 & 444.384 & 6.917 & 573.931 & 6.815 & & \\
\hline 272.608 & 6.566 & 375.412 & 7.301 & 447.581 & 6.908 & 577.615 & 6.799 & \multirow{3}{*}{\multicolumn{2}{|c|}{$\begin{array}{c}\text { Series III } \\
\Delta_{\mathrm{trs}} H_{\mathrm{m}} \text { Detn. B' }\end{array}$}} \\
\hline 275.439 & 6.575 & 378.281 & 7.339 & 450.800 & 6.902 & 581.298 & 6.807 & & \\
\hline 278.275 & 6.597 & 381.153 & 7.372 & 454.052 & 6.902 & 584.975 & 6.807 & & \\
\hline 281.106 & 6.610 & 384.026 & 7.399 & 457.309 & 6.902 & 588.652 & 6.813 & \multirow{3}{*}{\multicolumn{2}{|c|}{$\begin{array}{c}\text { Series IV } \\
\Delta_{\mathrm{rrs}} H_{\mathrm{m}} \text { Detn. } C\end{array}$}} \\
\hline 283.938 & 6.625 & 386.895 & 7.439 & 460.573 & 6.898 & 592.325 & 6.809 & & \\
\hline 286.772 & 6.643 & 389.758 & 7.475 & 463.856 & 6.894 & 595.993 & 6.801 & & \\
\hline 289.600 & 6.661 & 392.615 & 7.511 & 467.175 & 6.884 & 599.658 & 6.809 & \multirow{2}{*}{\multicolumn{2}{|c|}{$\begin{array}{c}\text { Series V } \\
T_{\mathrm{rrs}} \text { Detn. }\end{array}$}} \\
\hline 292.432 & 6.675 & 395.465 & 7.535 & 470.507 & 6.889 & 603.320 & 6.798 & & \\
\hline 295.268 & 6.693 & 398.307 & 7.582 & 473.857 & 6.875 & 606.976 & 6.807 & & \\
\hline 298.103 & 6.711 & 401.144 & 7.630 & 477.225 & 6.871 & 610.630 & 6.801 & & \\
\hline 300.939 & 6.735 & 403.976 & 7.655 & 480.610 & 6.870 & 614.286 & 6.793 & & \\
\hline \multicolumn{10}{|c|}{ Low-temperature measurements-Osaka University } \\
\hline Series & VI & 7.289 & 0.502 & 15.106 & 1.426 & 33.018 & 2.811 & 55.770 & 4.224 \\
\hline 2.430 & 0.007 & 7.702 & 0.563 & 15.904 & 1.488 & 34.507 & 2.926 & 57.314 & 4.297 \\
\hline 2.762 & 0.011 & 8.129 & 0.626 & 16.890 & 1.567 & 36.013 & 3.041 & 58.859 & 4.362 \\
\hline 3.018 & 0.016 & 8.597 & 0.694 & 17.941 & 1.659 & 37.507 & 3.160 & 60.407 & 4.425 \\
\hline 3.221 & 0.024 & 9.134 & 0.765 & 18.946 & 1.744 & 39.009 & 3.269 & 61.956 & 4.490 \\
\hline 3.431 & 0.034 & 9.829 & 0.871 & 19.972 & 1.815 & 40.514 & 3.372 & 63.508 & 4.552 \\
\hline 3.701 & 0.051 & 10.054 & 0.964 & 21.105 & 1.897 & 42.025 & 3.470 & 65.063 & 4.600 \\
\hline 4.031 & 0.077 & 11.178 & 1.045 & 22.229 & 1.981 & 43.538 & 3.562 & 66.619 & 4.656 \\
\hline 4.415 & 0.116 & 11.878 & 1.119 & 23.368 & 2.067 & 45.054 & 3.655 & 68.177 & 4.716 \\
\hline 4.819 & 0.156 & 12.612 & 1.190 & 24.553 & 2.156 & 46.575 & 3.750 & 69.737 & 4.765 \\
\hline 5.233 & 0.210 & 13.379 & 1.259 & 25.837 & 2.254 & 48.099 & 3.838 & 71.300 & 4.815 \\
\hline 5.652 & 0.265 & 14.196 & 1.352 & 27.234 & 2.361 & 49.628 & 3.919 & 72.863 & 4.860 \\
\hline 6.064 & 0.323 & \multirow{2}{*}{\multicolumn{2}{|c|}{ Series VII }} & 28.665 & 2.470 & 51.158 & 4.003 & 74.429 & 4.901 \\
\hline 6.465 & 0.381 & & & 30.121 & 2.583 & 52.692 & 4.077 & 75.995 & 4.947 \\
\hline 6.876 & 0.437 & 14.412 & 1.368 & 31.556 & 2.697 & 54.230 & 4.147 & & \\
\hline
\end{tabular}




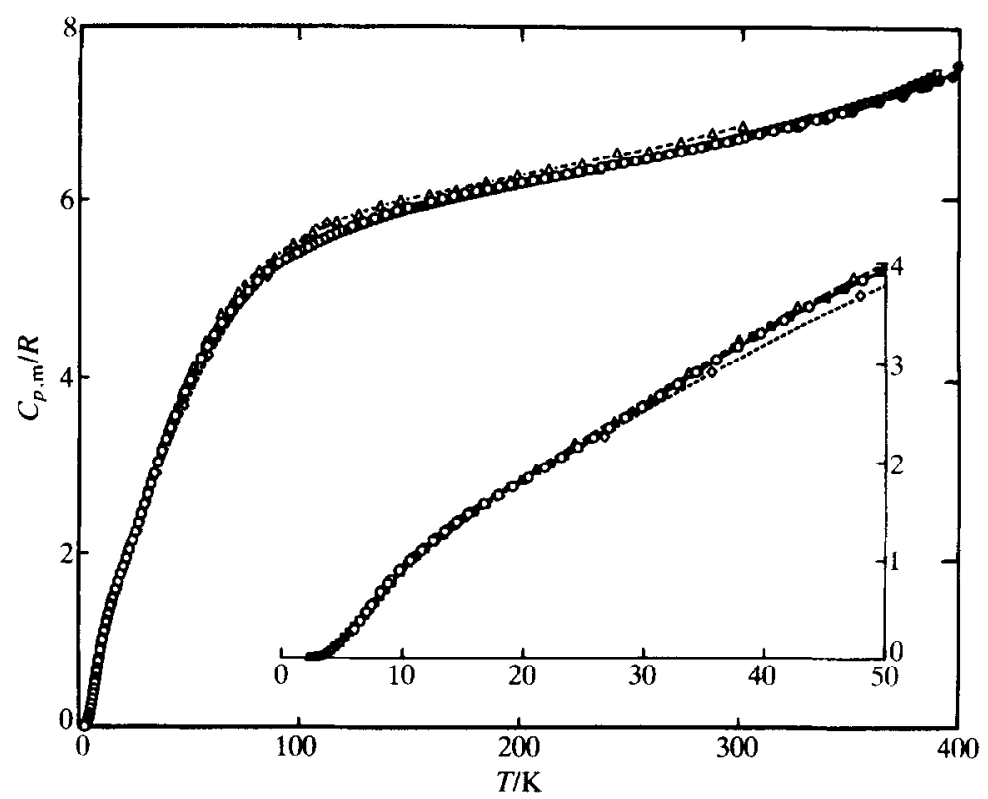

FIGURE 1. Subambient molar heat capacity of silver iodide: $O$. This research (U. of Michigan); . This research (U. of Oslo); $\square$, This research (Osaka University); $\triangle$. Pitzer, ${ }^{(18)} \diamond$, Nernst and Schwers; ${ }^{(17)} \longrightarrow$, Madison et al. ${ }^{(19)}$

single measurement from the smoothed heat capacity curve of about 0.15 per cent. Small corrections were applied for differences in mass of the silica-glass containers. The mass of the sample used was about $161.2 \mathrm{~g}$.

\section{Results}

\section{ANALYSIS OF RESULTS}

The lower-temperature heat capacities for AgI are listed in table 2 and plotted in figures 1 and 2. The results of the low-temperature Ann Arbor and Osaka experiments agree within experimental error with the heat capacity reported by Madison et $a l^{\left({ }^{(9)}\right)}$ for the very low end over the common range of measurement. Both the Osaka and the Ann Arbor results are in good accord over the range 7 to $350 \mathrm{~K}$ as shown on the above plot of figure 2 (see also Section 4). The experimental results reported here are about 2 per cent below the heat capacity reported for AgI by Pitzer. ${ }^{(18)}$ We confirm the presence of a "small wave" and the non-Debye behavior between 7 and $20 \mathrm{~K}$, that was reported earlier, as an abnormally high contribution (figure 1, inset).

The entropy and the enthalpy were evaluated by extrapolation of the heatcapacity curve to zero temperature and integrating. The experimental results for both the Osaka and the Oslo samples were averaged and then fitted to three polynomial segments: one of order 13 from 2.5 to $50 \mathrm{~K}$, a second of order 15 from 46 


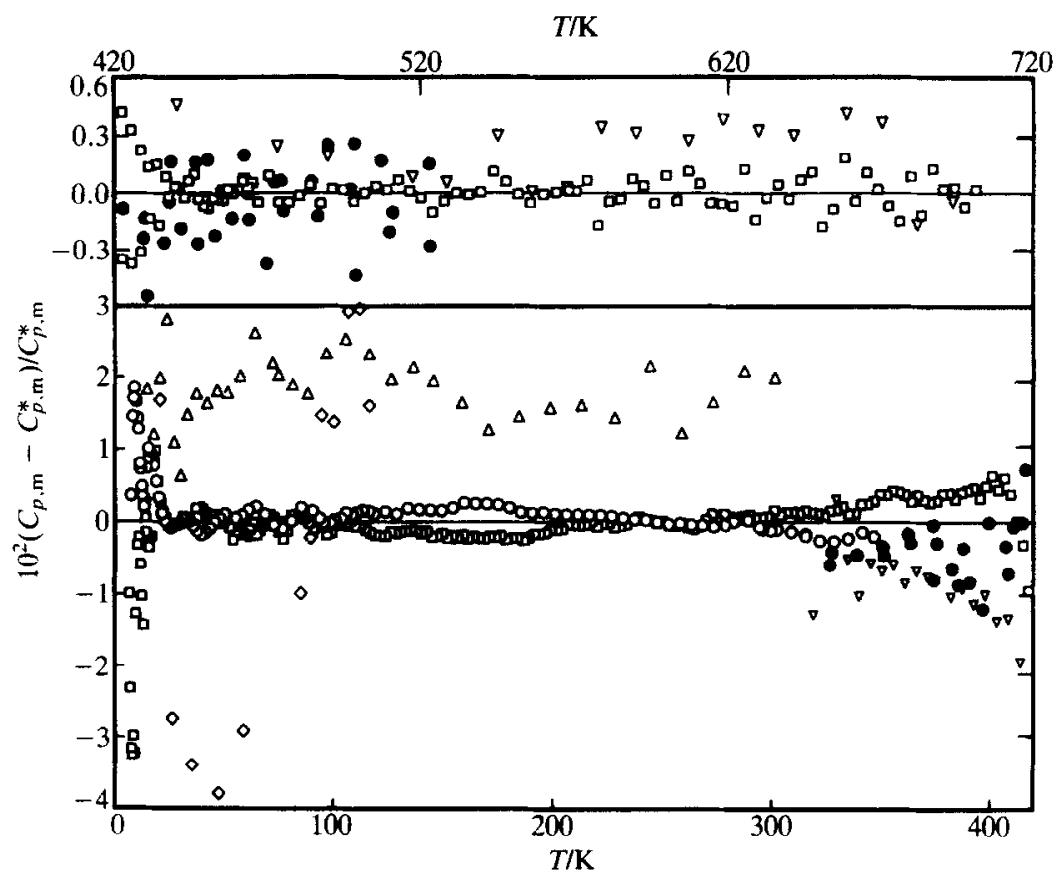

FIGURE 2. Deviations $\left(C_{p, \mathrm{~m}}-C_{p, \mathrm{~m}}^{*}\right) / C_{p, \mathrm{~m}}^{*}$ from smooth curve $\left(C_{p, \mathrm{~m}}^{*}\right.$ represents smooth values generated by the FITAB2 computer program from the mean value on the Osaka and the Oslo samples): $O$, this research (U. of Michigan); this research (U. of Oslo); $\sqcup$, this research (Osaka University): $\triangle$. Pitzer. ${ }^{\text {(18) }}$ $\diamond$. Nernst and Schwers, ${ }^{(17)} \nabla$. Nölting and Rein. ${ }^{(48)}$

to $170 \mathrm{~K}$, and a third of order 11 from 160 to $420 \mathrm{~K}$. There were at least three points of overlap between two neighboring segments and three artificial points at the extremities. The extrapolation from $2.4 \mathrm{~K}$ to zero included the experimental values reported by Madison et al., ${ }^{(10)}$ and the resulting entropy increment $\left\{S_{\mathrm{m}}^{\circ}(T)-S_{\mathrm{m}}(0)\right\}$ and enthalpy increment $\left\{H_{\mathrm{m}}^{\circ}(T)-H_{\mathrm{m}}^{\circ}(0)\right\}$ are $0.391 R$ and $2.890 R \cdot \mathrm{K}$ at $10 \mathrm{~K}$. The corresponding values at $298.15 \mathrm{~K}$ are $13.764 R$ and $1566.4 R \cdot \mathrm{K}$.

The higher-temperature experimental results (table 2 and figure 3 ) were fitted to one polynomial segment of order 13 from 422 to $700 \mathrm{~K}$. The results were found to be in excellent accord with those of Nölting and $\operatorname{Rein}^{(16)}$ for the $\alpha$-phase above $430 \mathrm{~K}$. In the transitional region the heat capacity was estimated from large-scale plots and integrated manually. The (partial) transitional evaluations are given in table 3 . A horizontal cut with $C_{p, \mathrm{~m}}=7.603 R$ was used as background level from 405 to $420.0 \mathrm{~K}$, whereas one with $C_{p, \mathrm{~m}}=6.922 R$ was used from 420.0 to $425 \mathrm{~K}$ (see Section 4). The thus defined (partial) transitional enthalpy and entropy were calculated from determinations $\mathrm{A}$ and $\mathrm{C}$, giving $\Delta_{405 \mathrm{~K}}^{425 \mathrm{~K}} H_{\mathrm{m}}^{\circ}=(758.7 \pm 0.8) R \cdot \mathrm{K}$ and $\Delta_{405 \mathrm{~K}}^{425 \mathrm{~K}} S_{\mathrm{m}}^{\circ}=$ $(1.814 \pm 0.018) R$. Determination $\mathrm{B}$ was not included due to the very long stabilization periods used, which makes the temperature drift during the experiments more important. The three Osaka determinations (table 3 ) are in close accord and their mean value is $(758.0 \pm 0.3) R \cdot \mathrm{K}$. Hence, the (overall) mean is $(758.4 \pm 0.5) R \cdot \mathrm{K}$. 


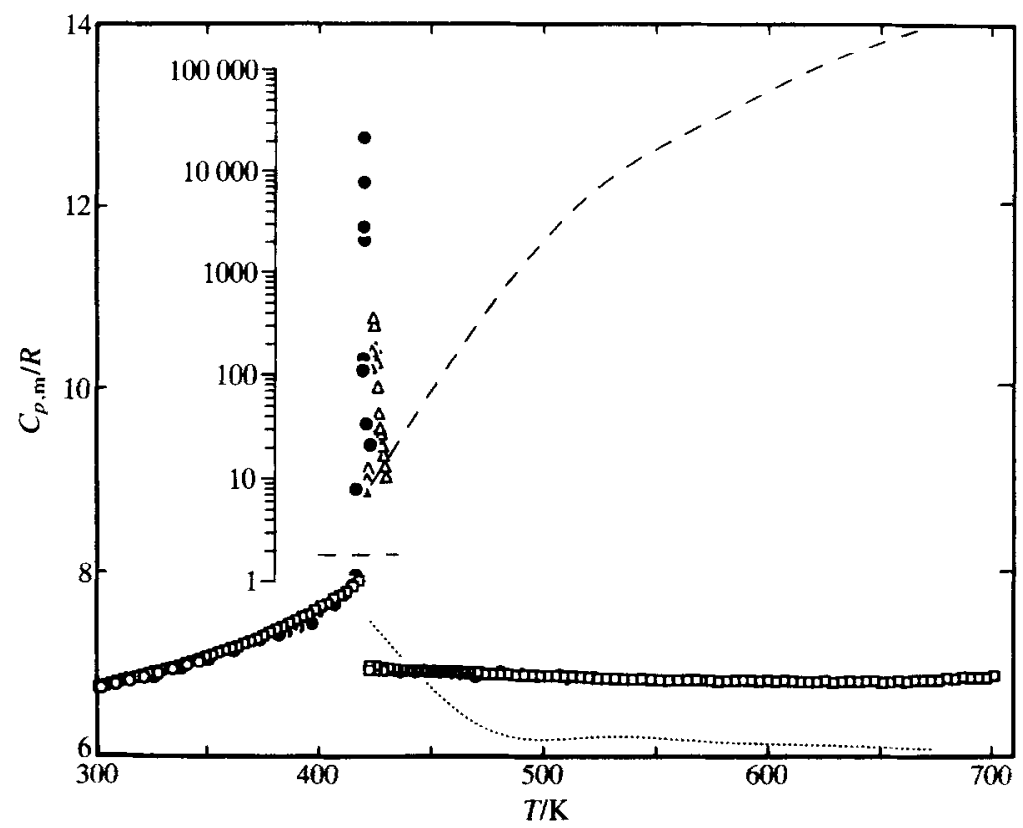

FIGURE 3. Superambient molar heat capacity of silver iodide: $\bigcirc$, this research (U. of Michigan); , this research (U. of Oslo); $\square$, this research (Osaka University); - - - Perrott and Fletcher, ${ }^{(7)}$ "stoichiometric" AgI; $\cdots$, Perrott and Fletcher, ${ }^{17)}$ "nonstoichiometric" AgI. (The logarithmic scale corresponds only to the transition region.)

The higher-temperature derived thermodynamic values based on the smoothed values are also given in table 4 at selected temperatures.

\section{Discussion}

\section{THE SUB-AMBIENT HEAT CAPACITY}

The results of this experiment were about 2 per cent lower than the results of similar measurements by Pitzer ${ }^{(18)}$ (figure 2) using isoperibol calorimetry. The deviations of Pitzer's points are shown on the same curve and the points are seen to be relatively less precise. Our measurements, however, form a very smooth curve with very small deviations throughout the region. Results of the determination of the heat capacity of silver iodide by Nernst and Schwers ${ }^{(17)}$ are lower than those of this study by 1 to more than 3 per cent for measurements below $90 \mathrm{~K}$ and are higher to about the same extent between 90 and $117 \mathrm{~K}$ (figure 2). Avogadro et al. ${ }^{(49)}$ published an approximation for the heat capacity of silver iodide by subtracting the heat capacity of $\mathrm{Ag}_{2} \mathrm{O} \cdot 2 \mathrm{~B}_{2} \mathrm{O}_{3}$ from that of $(\mathrm{AgI})_{0.5}\left(\mathrm{Ag}_{2} \mathrm{O} \cdot 2 \mathrm{~B}_{2} \mathrm{O}_{3}\right)_{0.5}$. The reliability of their results is such as to make their values consistent with both Pitzer's and our values and thus they cannot serve as a basis for judgment. At the very low end our results agree very well with a previous measurement by Madison et al.; ${ }^{(19)}$ their results however overlap with Pitzer's over only a small temperature range. 
TABLE 3. (Partial) enthalpies of transition of silver iodide; stabilization times $\tau$ $\left(R=8.3144 \mathrm{~J} \cdot \mathrm{K}^{-1} \cdot \mathrm{mol}^{-1}: M(\mathrm{AgI})=234.7727 \mathrm{~g} \cdot \mathrm{mol}^{-1}\right)$

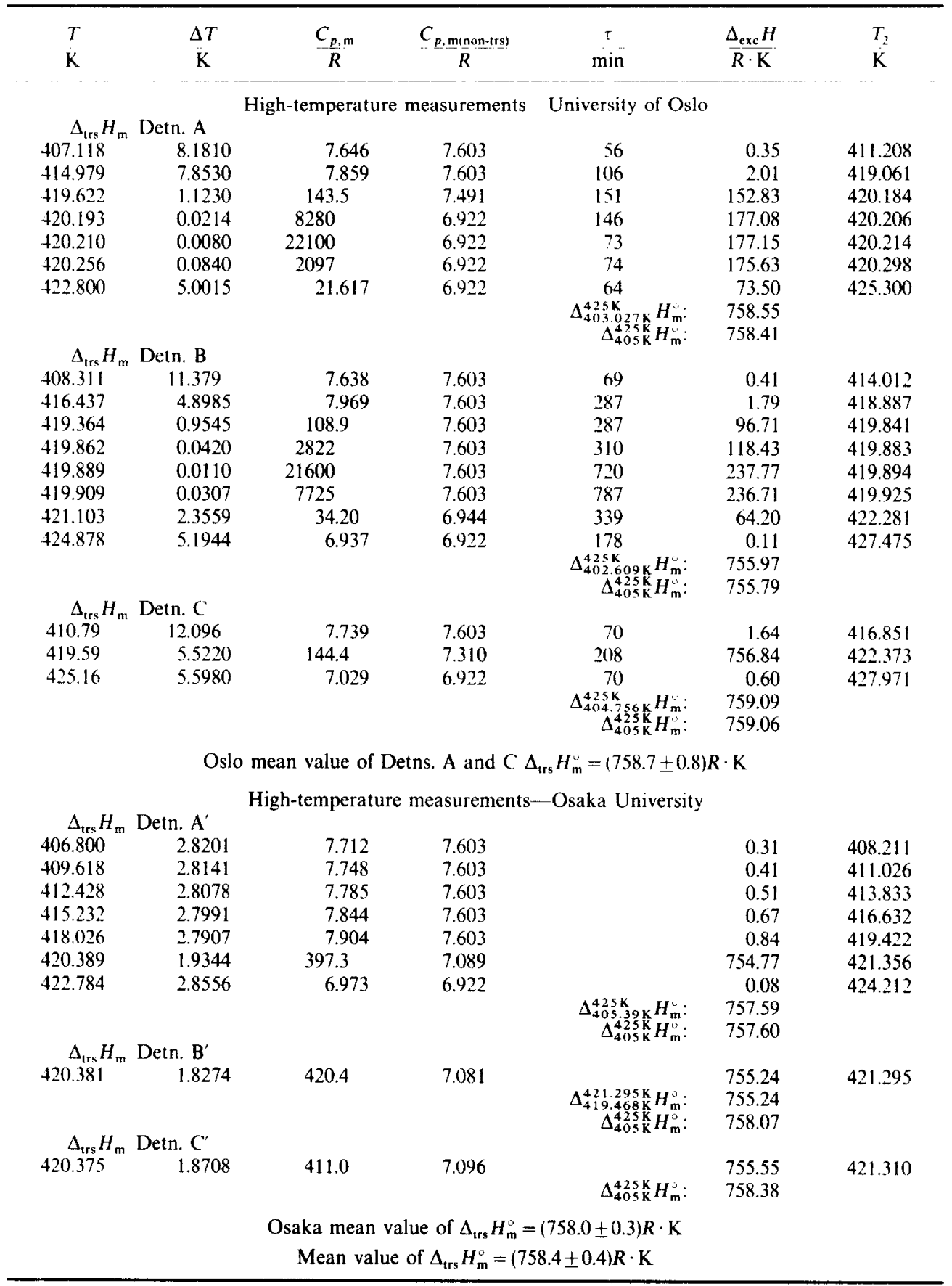


TABLE 4 . Thermodynamic properties at selected temperatures for silver iodide $\left(R=8.3144 \mathrm{~J} \cdot \mathrm{K}^{-1} \cdot \mathrm{mol}^{-1} ; M(\mathrm{AgI})=234.7727 \mathrm{~g} \cdot \mathrm{mol}^{-1}\right)$

\begin{tabular}{|c|c|c|c|c|c|c|c|c|c|}
\hline$\frac{T}{\mathrm{~K}}$ & $\begin{array}{c}C_{p . \mathrm{m}} \\
R\end{array}$ & $\frac{\Delta_{0}^{r} S_{\mathrm{m}}^{u}}{R}$ & $\frac{\Delta_{0}^{T}}{R \cdot \frac{H_{\mathrm{m}}^{\prime}}{\mathrm{K}}}$ & $\begin{array}{c}\Phi_{\mathrm{m}} \\
R\end{array}$ & $\begin{array}{l}T \\
\mathrm{~K}\end{array}$ & $\frac{C_{p, m}}{R}$ & $\frac{\Delta_{0}^{T} S_{\mathrm{m}}}{R}$ & $\begin{array}{c}\Delta_{0}^{T} H_{\mathrm{m}} \\
R \cdot \mathrm{K}\end{array}$ & $\begin{array}{c}\Phi_{\mathrm{m}}^{\prime} \\
R\end{array}$ \\
\hline \multicolumn{10}{|c|}{ Phase $\beta$} \\
\hline 0 & 0 & 0 & 0 & 0 & 170 & 6.031 & 10.207 & 751.0 & 5.789 \\
\hline 3 & 0.019 & 0.004 & 0.011 & 0.001 & 180 & 6.089 & 10.553 & 811.6 & 6.044 \\
\hline 5 & 0.177 & 0.044 & 0.178 & 0.008 & 190 & 6.142 & 10.884 & 872.8 & 6.290 \\
\hline 8 & 0.610 & 0.217 & 1.337 & 0.050 & 200 & 6.191 & 11.200 & 934.5 & 6.528 \\
\hline 10 & 0.904 & 0.391 & 2.890 & 0.102 & 210 & 6.239 & 11.503 & 996.6 & 6.758 \\
\hline 15 & 1.420 & 0.863 & 8.796 & 0.276 & 220 & 6.287 & 11.795 & 1059.2 & 6.980 \\
\hline 20 & 1.807 & 1.325 & 16.875 & 0.481 & 230 & 6.337 & 12.075 & 1122.4 & 7.196 \\
\hline 25 & 2.191 & 1.770 & 26.871 & 0.695 & 240 & 6.389 & 12.346 & 1186.0 & 7.405 \\
\hline 30 & 2.574 & 2.203 & 38.782 & 0.910 & 250 & 6.441 & 12.608 & 1250.1 & 7.608 \\
\hline 35 & 2.965 & 2.629 & 52.63 & 1.125 & 260 & 6.493 & 12.862 & 1314.8 & 7.805 \\
\hline 40 & 3.331 & 3.049 & 68.39 & 1.340 & 270 & 6.545 & 13.108 & 1380.0 & 7.997 \\
\hline 45 & 3.652 & 3.461 & 85.86 & 1.552 & 280 & 6.599 & 13.347 & 1445.7 & 8.183 \\
\hline 50 & 3.939 & 3.861 & 104.86 & 1.763 & 290 & 6.657 & 13.579 & 1512.0 & 8.366 \\
\hline 60 & 4.417 & 4.623 & 146.75 & 2.177 & 298.15 & 6.707 & 13.764 & 1566.4 & 8.511 \\
\hline 70 & 4.771 & 5.332 & 192.77 & 2.578 & 300 & 6.718 & 13.806 & 1578.9 & 8.543 \\
\hline 80 & 5.054 & 5.988 & 241.94 & 2.964 & 325 & 6.883 & 14.350 & 1748.9 & 8.969 \\
\hline 90 & 5.264 & 6.596 & 293.60 & 3.334 & 350 & 7.053 & 14.866 & 1923.0 & 9.372 \\
\hline 100 & 5.412 & 7.159 & 347.01 & 3.689 & 375 & 7.275 & 15.36 & 2101.9 & 9.755 \\
\hline 110 & 5.543 & 7.681 & 401.79 & 4.028 & 400 & 7.567 & 15.84 & 2287.4 & 10.120 \\
\hline 120 & 5.661 & 8.168 & 457.83 & 4.353 & 405 & 7.603 & 15.93 & 2325.3 & 10.189 \\
\hline 130 & 5.752 & 8.625 & 514.9 & 4.664 & 410 & 7.603 & 16.03 & 2363.3 & 10.266 \\
\hline 140 & 5.836 & 9.054 & 572.8 & 4.963 & 415 & 7.603 & 16.12 & 2401.3 & 10.334 \\
\hline 150 & 5.911 & 9.460 & 631.6 & 5.249 & 420 & 7.603 & 16.21 & 2439.3 & 10.402 \\
\hline 160 & 5.971 & 9.843 & 691.0 & 5.524 & & & & & \\
\hline \multicolumn{10}{|c|}{ Phase $\alpha^{a}$} \\
\hline 420 & 6.922 & 18.02 & 3199.6 & 10.402 & 550 & 6.810 & 19.87 & 4091.2 & 12.431 \\
\hline 425 & 6.922 & 18.10 & 3232.3 & 10.495 & 600 & 6.803 & 20.46 & 4431.6 & 13.074 \\
\hline 450 & 6.908 & 18.50 & 3405.2 & 10.932 & 650 & 6.797 & 21.01 & 4771.3 & 13.670 \\
\hline 475 & 6.877 & 18.87 & 3578.5 & 11.336 & 700 & 6.850 & 21.51 & 5112 & 14.207 \\
\hline 500 & 6.859 & 19.22 & 3749.5 & 11.721 & & & & & \\
\hline
\end{tabular}

${ }^{a}$ Assuming an isothermal transition.

The agreement between the heat-capacity values for the Osaka sample and the Oslo sample is good only below $100 \mathrm{~K}$ and in the $\alpha$-phase. The heat capacity of the Osaka sample is lower than that of the Oslo sample between 100 and $300 \mathrm{~K}$, and is higher between 300 and $420 \mathrm{~K}$ (see figure 2). These deviations are slightly larger than experimental error and might be due to the different thermal histories of the samples. The Osaka sample on which the subambient measurements were made was synthesized by a gel method and was heated only to $700 \mathrm{~K}$. The Oslo sample was synthesized at high temperatures and was annealed before the measurement. After annealing of the Osaka sample at $700 \mathrm{~K}$ essentially identical heat capacities were obtained on both samples below $70 \mathrm{~K}$ (see table 2 for thermal history).

The $C_{p, \mathrm{~m}} / R$ curve (figure 1) is nearly linear from 10 to $50 \mathrm{~K}$. The $C_{p, \mathrm{~m}} / R T$ against $T^{2}$ curve (figure 4) rises sharply at temperatures lower than $8 \mathrm{~K}$ and levels off to 


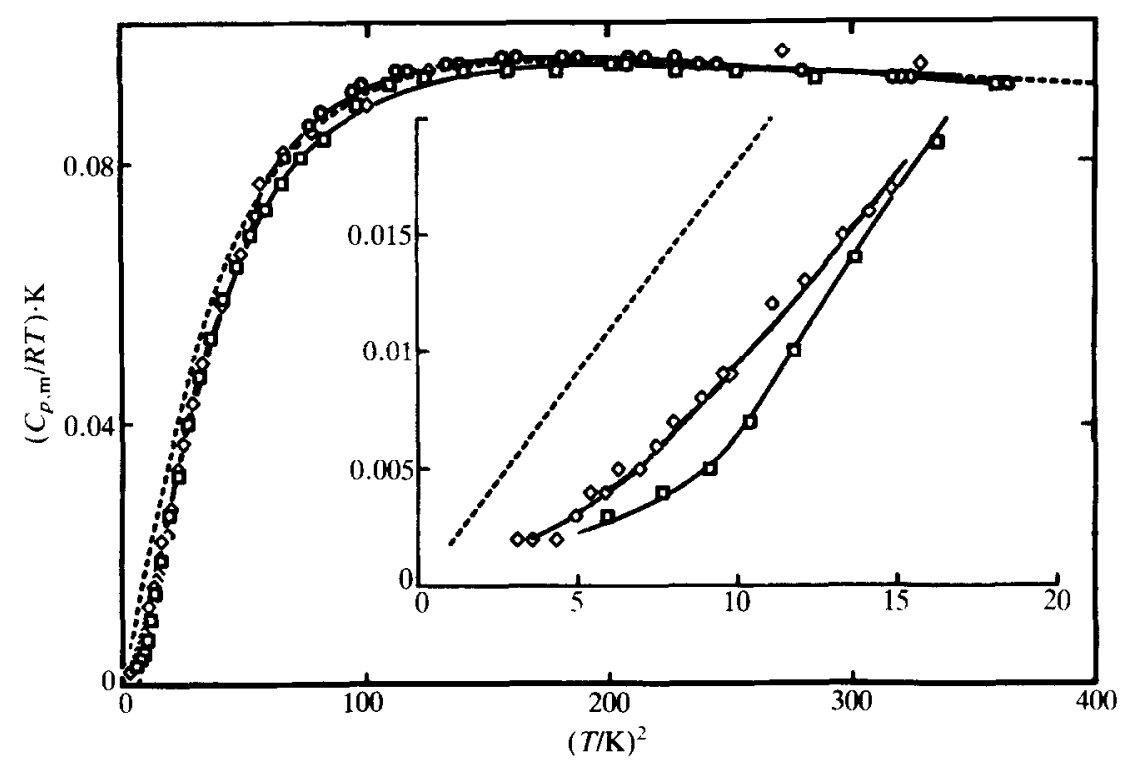

FIGURE 4. $C_{p, m} / R T$ against $T^{2}$ for silver iodide: $O$, this research (U. of Michigan); $\square$, this research (Osaka University): $\diamond$, Madison et al.(19) $\ldots$-., calculated using the LEM-2 program based on $\Theta_{\mathrm{KW}}=34 \mathrm{~K}$.

nearly a constant value between 10 and $20 \mathrm{~K}$ indicating that the heat capacity rises almost linearly with temperature over the region. Above $20 \mathrm{~K}, C_{p, \mathrm{~m}} / R T$ gradually decreases by 5 per cent between 20 and $30 \mathrm{~K}$ by 8 per cent between 30 and $50 \mathrm{~K}$. An early explanation ${ }^{(18)}$ of this phenomenon suggests a severely anharmonic fiveminima potential function for the silver ions. ${ }^{(50)}$ However, a potential function with a single minimum at the center of the tetrahedron of iodide ions was subsequently developed by Cava et al. ${ }^{(42)}$ and X-ray diffractional evidence for such a function was provided by Burley. ${ }^{(36)}$.

This "non-Debye" behavior results from a "non-Debye" phonon density of states $g(\omega)$ as shown by Bührer et al. ${ }^{(51)}$ who used a density-of-states function that was derived from the experimental phonon-dispersion relations measured by inelastic neutron scattering. The lattice heat capacity based on this density-of-states function agrees well with our experimental results below $60 \mathrm{~K}$. Above $60 \mathrm{~K}$ deviation of $C_{r}$ from $C_{V}$ becomes significant.

The apparent $\Theta_{D}$ in the region below $60 \mathrm{~K}$ varies several fold. (At higher temperatures $\Theta_{\mathrm{D}}$ drops to zero when the heat capacity exceeds the Dulong and Petit limit.) Between 7 and $50 \mathrm{~K}$ a computer-aided approximation to represent the temperature dependence of the heat capacity based on a several-parameter phonondistribution function ${ }^{(52)}$ yielded a characteristic temperature $\left(\Theta_{\mathrm{KW}}\right)$ which is constant (figure 5) indicating that a good approximation to $g(\omega)$ has been achieved. An attempt to extend this approximation below $7 \mathrm{~K}$, using the heat capacity reported by Madison et al. yielded a sharp upward trend in $\Theta_{\mathrm{KW}}$ as well as in $\Theta_{\mathrm{D}}$. We note that change in $\Theta_{\mathrm{D}}$ is much larger than in $\Theta_{\mathrm{KW}}$. We also note that the experimental 


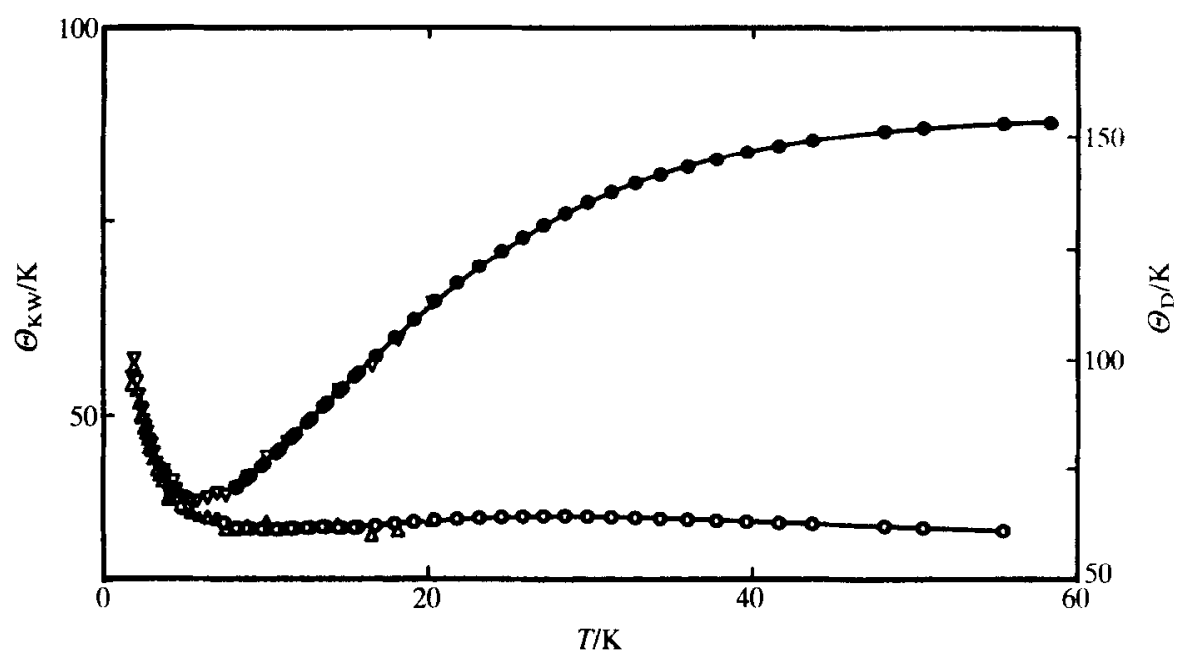

FIGURE 5. Apparent characteristic temperatures $\Theta_{\mathrm{D}}$ and $\Theta_{\mathrm{KW}}$ for silver iodide: (a) $\Theta_{\mathrm{KW}}$ : $O$, this research (U. of Michigan); $\triangle$, Madison et al. ${ }^{(19)}$ (b) $\Theta_{\mathrm{D}}: \Theta^{-}$, this research (U. of Michigan); $\nabla$. Madison et $a l^{(19)}$ The Osaka points (which agree well) are not shown to avoid an even greater density of points.

heat-capacity values are significantly lower than those predicted by both the theoretically approximated and the experimental ${ }^{(51)}$ phonon distribution of states, and are closer to the values predicted by the theoretical approximation. The fact that the experimental heat capacity is lower than the heat capacity predicted both by the experimental distribution function and the theoretical approximation- $\Theta_{\mathbf{K W}}-$ provides a convincing argument for the absence of any special contribution - such as the sought precursor indication of the fast ion state ${ }^{(19)}$ - in the heat capacity.

\section{THE SUPER-AMBIENT HEAT CAPACITY - ENTHALPY OF TRANSITION}

The experimentally determined heat capacity of silver iodide can, to a first approximation, be represented by a sum of three contributions:

$$
C_{\mathrm{obs}}=C_{V}+C_{\mathrm{d}}+C_{\mathrm{trs}} \text {. }
$$

Here $C_{V}$ is a constant-volume heat capacity in the harmonic approximation, arbitrarily calculated using a (constant) Debye temperature (taken as the maximum of $\Theta_{\mathrm{D}}$-equal to $150 \mathrm{~K}$-in a plot of $\Theta_{\mathrm{D}}$ against temperature). A calculated $C_{\mathrm{d}}=T V \alpha^{2} / \kappa$ accounts for anharmonic vibrations, whereas $C_{\mathrm{trs}}$ represents the premonitory contribution to the structural-disordering phase transition taking place near $420 \mathrm{~K}$.

The constant Debye temperature is in good agreement with that calculated from elastic constants. ${ }^{(53)}$ The dilational contribution was estimated using the temperature dependence of the molar volume $V_{\mathrm{m}}$ and the isobaric expansivity $\alpha$ obtained by Lieser $^{(54)}$ in the temperature range 5 to $420 \mathrm{~K}$. The isothermal compressibility 


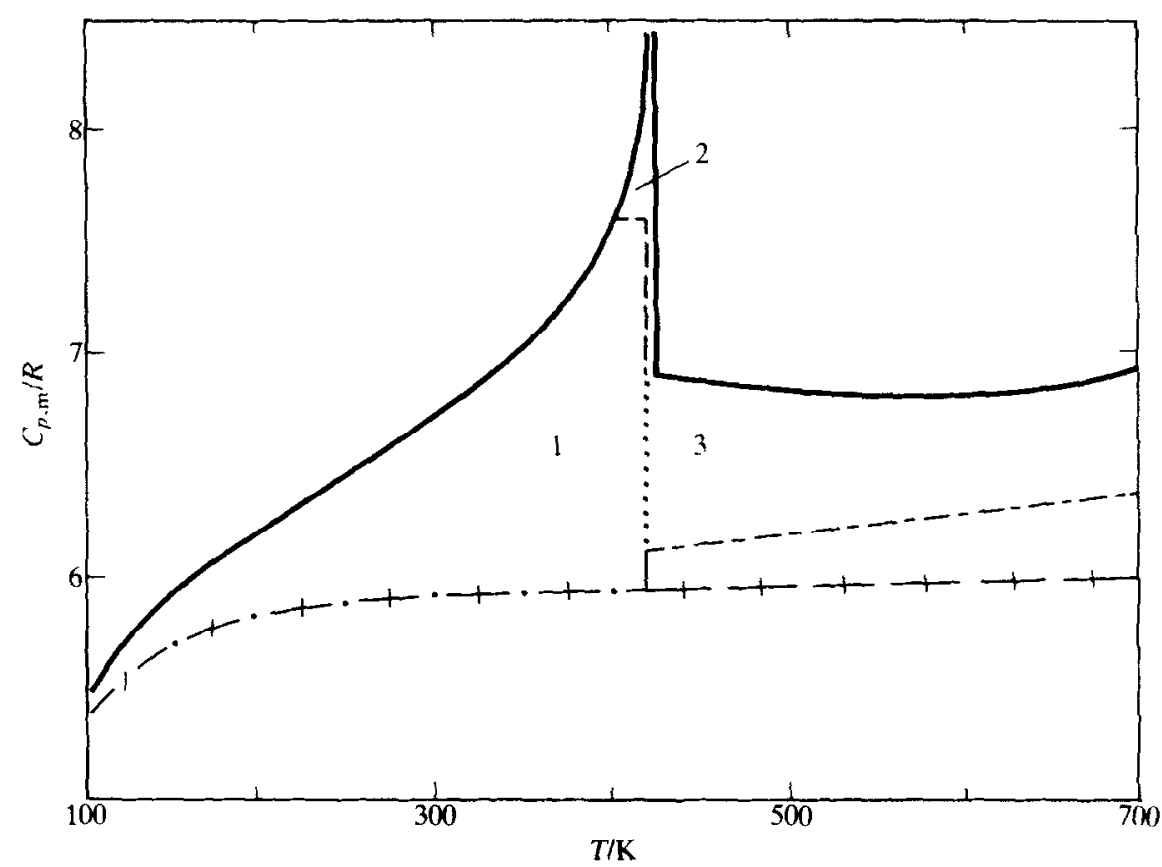

FIGURE 6. Resolution of the heat capacity of silver iodide.,$+++ C_{V, \mathrm{~m}} ;-\cdots, C_{p, \mathrm{~m}}$ (lattice); observed $C_{p, m} ; 1$, "pre-transitional" area $(221 K \cdot K) ; 2$, transitional area $(759 K \cdot K) ; 3$, "post-transitional" area $(165 R \cdot \mathrm{K})$.

$\kappa=4.0 \times 10^{-11} \mathrm{~Pa}^{-1}$, obtained for the $\beta$-phase ${ }^{(55)}$ at ambient temperature was assumed to be valid (and is essentially confirmed by the value $4.17 \times 10^{-11} \mathrm{~Pa}^{-1}$ at $295 \mathrm{~K}) .^{(56)}$ With identical molar volumes and differences only in the stacking sequences, the $\gamma$-and $\beta$-AgI have practically the same heat-capacity behavior and transition temperature. Nölting and Rein ${ }^{(16)}$ reported both transition temperatures to be the same within $\pm 0.5 \mathrm{~K}$, whereas Weiss ${ }^{(57)}$ reported $417.7 \mathrm{~K}$ for the $(\beta$ to $\alpha)$ transition and $420.2 \mathrm{~K}$ for the $(\gamma$ to $\alpha)$-transition, but Yamada ${ }^{(58)}$ and Hoshino ${ }^{\{3\}}$ reported the reverse: ( 421 to $409 \mathrm{~K}$, respectively). In the $\alpha$-phase region the expansivity results by $\operatorname{Lawn}^{(29)}$ were used together with compressibilities derived from the elastic-constant determinations by Börjesson ${ }^{(59)}$ and by Börjesson and Torell ${ }^{(60)}\left(k=7.41 \times 10^{-11} \mathrm{~Pa}^{-1}\right.$ at $\left.613 \mathrm{~K}\right)$. The thus calculated contributions to the heat capacity are given in figure 6 . At low temperatures the very small value of the expansitivity gives a negligible dilational contribution.

The present interpretation implies a more gradual transition than assumed previously. The continuous disordering process gives rise to an appreciable "pretransitional" heat-capacity contribution-which is clcarly perceptible at $100 \mathrm{~K}$ (sec figure 6)-and a correspondingly high fraction of the transitional enthalpy, $220.8 R \cdot \mathrm{K}$, in the range 100 to $420 \mathrm{~K}$ (Area 1, figure 6) after subtraction of the more cooperative part of the transition (Area 2, figure 6). The low-temperature process, which results in a continuously increasing mole fraction of "defects", may at a given 


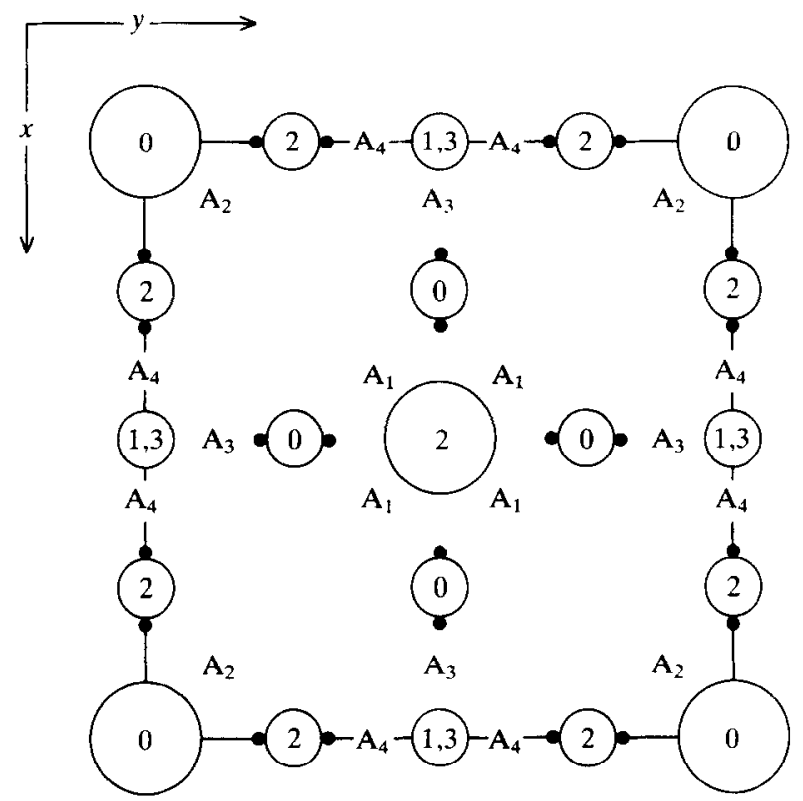

FIGURE 7. Projection of the $\alpha$-phase structure in the $x y$-plane, with alternative $\mathrm{Ag}^{+}$positions indicated. Large circles represent $\mathbf{I}^{-}$ions in positions $2 \mathrm{a} 0,0,0,1 / 2,1 / 2,1 / 2$; of space group $\operatorname{Im} 3 \mathrm{~m}$. The $z$ parameters are expressed as $z / 4$. Small circles represent $\mathrm{Ag}^{+}$ions in tetrahedral centers $12 \mathrm{~d}$ with $z / 4$ parameters indicated. The $6 \mathrm{~b}$ positions are centered between the $12 \mathrm{~d}$ positions. The $24 \mathrm{~g}$ displaced tetrahedral positions are indicated by when displaced in the $x$ or $y$ directions-with $z$ unchanged, but are not indicated when displaced in the $z$ direction. The $24 \mathrm{~h}$ triangularly coordinated positions are indicated by $A_{1}(z=0), A_{2}(z=1 / 2), A_{3}(z=0.11$ and 0.89$)$, and $A_{4}(z=0.39$ and 0.61$)$.

defect mole fraction trigger a first-order transition mechanism. ${ }^{(61,62)}$ The partial enthalpy determinations given in table 3 , hence, represent only the more cooperative part of the order-disorder process. In addition, a considerable "post-transitional" enthalpy contribution, $165 R \cdot \mathrm{K}$, originates from decay of short-range order and exitation of soft modes, linearly extrapolated above the transition temperature in the range 420 to $695 \mathrm{~K}$. The total enthalpy of transition, over the entire range in which excess contribution is present, is $1150 \mathrm{R} \cdot \mathrm{K}$, whereas the corresponding entropy is $2.872 R$.

The structure of $\alpha$-AgI was described by Strock $^{(63)}$ in terms of random distribution of the two $\mathrm{Ag}^{+}$ions in the unit cell over 30 positions, and in the latter ${ }^{(63)}$ over 42 positions in the space group $\operatorname{Im} 3 \mathrm{~m}$ (No. 229). In this structure (see figure 7) the $\mathrm{Ag}^{+}$ ion in positions $6 \mathrm{~b}(0,1 / 2,1 / 2 ;$ etc. $)$ are octahedrally surrounded by the $\mathrm{I}^{-}$ions in $2 \mathrm{a}$ $(0,0,0 ; 1 / 2,1 / 2,1 / 2)$, while the $\mathrm{Ag}^{+}$ions in $12 \mathrm{~d}(1 / 4,0,1 / 2 ;$ etc. $)$ are tetrahedrally surrounded, and those in $24 \mathrm{~h}(0, y, y$; etc. with $y=0.39)$ are triangularly surrounded by $\mathrm{I}^{-}$ions. The correctness of this model was adhered to by Hoshino, ${ }^{(13)}$ while later powder neutron-diffraction studies by Bührer and Hälg ${ }^{(64)}$ discredited the Strock model in favor of the $\mathrm{Ag}^{+}$ions being located at displaced tetrahedral $24 \mathrm{~g}$ sites $(x, 0,1 / 2 ;$ etc., with $x=0.193)$. The different alternatives were reconsidered in the single-crystal neutron-diffraction study by Cava et $a l .^{(42)}$ and the alternative with all 
$\mathrm{Ag}^{+}$ions residing in the tetrahedrally coordinated $12 \mathrm{~d}$ positions with large anharmonic vibrations was found to agree best with the experimental results. The same conclusion was deduced by Hoshino et al. ${ }^{(65)}$ from a powder neutrondiffraction study as well as upon reconsideration of the earlier X-ray results ${ }^{(13)}$ in light of the EXAFS study by Boyce et al ${ }^{(66)}$ This study showed that the $\mathrm{Ag}^{+}$ion distribution was about $10 \mathrm{pm}$ from the tetrahedral center and displaced toward a tetrahedral face. Furthermore, the residence time of the $\mathrm{Ag}^{+}$ions in the displaced tetrahedral site is roughly 3 times the flight time between different tetrahedra at $470 \mathrm{~K}$. Thus, the early conclusions about position and dynamics of the $\mathrm{Ag}^{+}$ions from X-ray ${ }^{(1,2,13)}$ and neutron-diffraction ${ }^{(64)}$ studies were found to be inconsistent with the EXAFS results.

Accordingly, the disordering of the $\mathrm{Ag}^{+}$ions in the $\alpha$-AgI phase concerns configurations formed by distributing $\mathrm{N} \mathrm{Ag}^{+}$ions over $6 \mathrm{~N}$ tetrahedral sites. It is further argued by Beyeler et al. ${ }^{(67)}$ that since the phonon frequencies do not change much from the $\beta$ - to the $\alpha$-phase, and that the disorder is negligibly small in the $\beta$-phase, the transitional entropy is mainly given by the disorder entropy of the $\alpha$-phase. The limiting entropy increment is then $R \cdot \ln 6$ for AgI, or $1.79 R$. Unrestricted disorder of the $\mathrm{Ag}^{+}$ions is unattainable, however, as the nearest $\mathrm{Ag}^{+}$ tetrahedral neighbor sites are only $179 \mathrm{pm}$ apart.

An important result of the present study is that a considerable local structuraldisorder entropy accumulates in $\beta$-AgI before it transforms to $\alpha-\mathrm{AgI}$ (amounting to about $0.7 R$ over the range 100 to $420 \mathrm{~K}$ ). Thus, our estimate of the structuraldisorder entropy in $\alpha$-AgI considerably exceeds the limiting disorder entropy already at $425 \mathrm{~K}$ by $0.7 R$. Part of the reason may be ascribed to differences in bonding energy of $\beta$ - and $\alpha-A g I$, but the fact remains that the $\Lambda g^{+}$ions are structurally largely disordered, and little additional structural disorder entropy will be acquired by further redistribution of the $\mathrm{Ag}^{+}$ions.

Comparison with 18 previously published enthalpy-of-transition determinations are given in table 5. The difference between "total" and "partial" transitional functions are seen in figure 6 as the sum of Areas 1, 2, and 3 for which the respective $\Delta_{\mathrm{trs}} S_{\mathrm{m}} \mathrm{s}$ are $0.7 R, 1.81 R$, and $0.30 R$.

It should be noted that the $(\beta / \gamma$ to $\alpha)$-transition does not occur at a well defined temperature, but depends slightly on the previous thermal history of the sample. Thus, the transition temperature for the Oslo sample in $\Delta_{\mathrm{trs}} H_{\mathrm{m}}$ (Detn. A) is about $0.3 \mathrm{~K}$ higher than in $\Delta_{\mathrm{trs}} H_{\mathrm{m}}$ (Detn. B) for the same fraction transformed.

\section{DEFECT MODELS}

Several models for analyzing the excess heat capacity have been proposed. According to Jost, ${ }^{(81)}$

$$
\Delta_{\mathrm{def}} C_{p, \mathrm{~m}} T^{2}=\left\{\exp \left(\Delta_{\mathrm{def}} S_{\mathrm{m}} / 2 R\right)\right\}\left\{\left(\Delta_{\mathrm{def}} H_{\mathrm{m}}\right)^{2} / 2 R\right\} \cdot \exp \left(-\Delta_{\mathrm{dcf}} H_{\mathrm{m}} / 2 R T\right) .
$$

Hence, by plotting $\lg \left(\Delta_{\mathrm{def}} C_{p, \mathrm{~m}} T^{2}\right)$ against $1 / T$, the enthalpy and entropy of defect formation are easily found, giving $\Delta_{\mathrm{def}} H_{\mathrm{m}}=250 R \cdot \mathrm{K}$ and $\Delta_{\mathrm{def}} S_{\mathrm{m}}=0.91 R$, as the mean values over the range 250 to $400 \mathrm{~K}$. The change in slope indicates that more 
TABLE 5. (Partial) enthalpy of the $420 \mathrm{~K}$ disordering phase transition $(\beta / \gamma$ to $x)$-AgI

\begin{tabular}{|c|c|c|c|c|}
\hline $\begin{array}{l}T \\
\mathrm{~K}\end{array}$ & $\frac{\Delta_{\mathrm{trs}} H_{\mathrm{m}}}{R \cdot \mathrm{K}}$ & Method & Authors & Year \\
\hline 423 & 740 & Drop calorimetry & Bellati and Romanese ${ }^{68 \mid}$ & 1882 \\
\hline 418 & 805 & Drop calorimetry & Mallard and Le Chatelier ${ }^{(69)}$ & 1883 \\
\hline 418 & 681 & Clapeyron & Bridgman $^{\{70\}}$ & 1915 \\
\hline \multirow[t]{2}{*}{419.8} & 639 & e.m.f. & Cohen and Joss ${ }^{(71)}$ & 1928 \\
\hline & $749 \pm 15$ & & Hennicke $^{(72)}$ & 1938 \\
\hline 42.2 .5 & 760 & Adiabatic calorimetry & Lieser $^{(12)}$ & 1954 \\
\hline 421 & 770 & Adiabatic calorimetry & Hoshino $^{(13\}}$ & 1957 \\
\hline 419.7 & $610 \pm 70$ & Clapeyron & Majumdar ${ }^{(73)}$ & 1958 \\
\hline 419.7 & $610 \pm 70$ & Clapeyron & Majumdar and Roy ${ }^{(74)}$ & 1959 \\
\hline 420.4 & 712 & Adiabatic calorimetry & Nölting(15) & 1963 \\
\hline 419 & $760 \pm 50$ & d.t.a. & Rao and $\operatorname{Rao}^{(75)}$ & 1966 \\
\hline 420 & $780 \pm 25$ & d.t.a. & Berger et al. ${ }^{(76)}$ & 1967 \\
\hline 423 & $760 \pm 50$ & Adiabatic calorimetry & Perrott and Fletcher ${ }^{(6)}$ & 1968 \\
\hline 423 & $755^{-}$ & Drop calorimetry & Carré et al. ${ }^{(77)}$ & 1969 \\
\hline 421 & $740 \pm 35$ & Adiabatic calorimetry & Nölting and Rein ${ }^{(16)}$ & 1969 \\
\hline \multirow[t]{2}{*}{419} & 1010 & d.t.a. & Natarajan and Rao ${ }^{(78)}$ & 1970 \\
\hline & 729 & d.s.c. & Mellander et al..$^{799)}$ & 1981 \\
\hline 421 & $650 \pm 250$ & e.m.f. & Quoranta and Bazán ${ }^{\{0\}}$ & 1983 \\
\hline 420.0 & $758 . \overline{7} \pm 0.8$ & Adiabatic calorimetry & Present work (Oslo) & 1989 \\
\hline 420.0 & $758.0 \pm 0.3$ & Adiabatic calorimetry & Present work (Osaka) & 1989 \\
\hline
\end{tabular}

than one defect-formation process is taking place. The observed defect-formation enthalpy is only 25 per cent of that calculated by Jost et al. ${ }^{(14)}$ and only 19 per cent of that claimed by Nölting and Rein. ${ }^{(16)}$ This is due at least in part to the different choice of non-transitional heat-capacity curves. In the present evaluation a physical approximation is used, giving $C_{\text {(non-trs) }}=C_{V}+C_{\mathrm{d}}$. In the earlier investigations, the non-transitional heat capacity was extrapolated from experimental $C_{p, \mathrm{~m}}$ values $^{(14,16)}$ closer to the transition temperature. Thus transitional contributions were considered only in a narrow range near the transition temperature. The presently obtained small value of $\Delta_{\text {def }} H_{\mathrm{m}}$ might imply the presence of a "large" fraction of defects even below the order-disorder temperature-in agreement with the appreciable ionic conductivity in the same temperature range.

The present interpretation of the excess heat capacity is based on the classical concept of atomic diffusion in solids, where a diffusing ion traverses a barrier with height given by the activation energy. A basic assumption is then that the time spent on a lattice site is much greater than the time spent between the potential-energy minima. However, it has been shown that the probability of finding mobile ions at saddle-point positions is large in fast ionic conductors (see e.g. reference 82). Hence, the applicability to the present compound of the normal jump model, where atoms take well defined sites, is doubtful.

\section{THE REPORTED $700 \mathrm{~K}$ TRANSITION}

As may be noted in figure 6 a significant post-transitional heat-capacity contribution appears to be present. Fontana et al.'s ${ }^{(21)}$ Raman spectra show a pronounced 
decrease over the range 590 to $650 \mathrm{~K}$ interpreted by Mariotto et al..$^{(22)}$ as further disordering or "melting" of the silver sublattice. Brillouin spectra determinations by Börjesson and Torell ${ }^{(59)}$ confirm abrupt changes in the trend of the temperature dependence of the longitudinal-mode frequencies near $650 \mathrm{~K}$ (although the transverse-mode frequencies are unaffected) attributed to redistribution of silver ions from tetrahedral to trigonal and octagonal sites yielding an isotropic distribution. Mazzacurati et al. ${ }^{(28)}$ proposed also that near $700 \mathrm{~K}$ the distribution of silver ions becomes homogeneous and isotropic. The model of Huberman and Martin ${ }^{(83)}$ on pseudospin densities involves redistribution among energetically equivalent sites whether or not crystallographically equivalent. The observation of Börjesson and Torell $^{(60)}$ favors a redistribution which also includes the jumping of silver ions hetween equivalent tetrahedral and non-equivalent trigonal and octahedral sites.

Modelers tend to relate their interpretations to the cooperative transition near $700 \mathrm{~K}$ reported by Perrott and Fletcher ${ }^{(6-10)}$ as involving $(151 \pm 25) R \cdot \mathrm{K}$ of isothermal transitional enthalpy plus an additional approximately $1500 R \cdot \mathrm{K}$ "excess" inter-transitional enthalpy \{between the $(\beta$ to $\alpha)$ and $700 \mathrm{~K}$ transitions\}. However, a total enthalpy increment of this magnitude is too great to be reconciled with the further disordering of silver ions or with the calorimetric results of this research and that of others ${ }^{(14,16.48)}$ (see figure 3) on the magnitude and trend of the heat capacity between the ( $\beta$ to $\alpha)$-transition and melting. The post- $(\beta / \alpha)$-transitional enthalpy of this research approximates $63 R \cdot \mathrm{K}$ (Area 3, figure 6) over the range 425 to $700 \mathrm{~K}$ and corresponds more reasonably to theoretical entropy-increment estimates. The present observations indicate disorder corresponding to a transitional entropy increment of $R \cdot \ln 12$, i.e. distribution on about 24 positions in the unit cell. Further population of 24 sites requires only $0.69 R$, while Perrott and Fletcher's ${ }^{16} 101$ additional transition gives about $2 R$ ! The approximately constant trend of our heat capacities above the ( $\beta$ to $\alpha$ )-transition (actually gently concave upwards) probably involves a decrease in post-transitional disordering contribution plus the growing size of the contribution related to the softening in the $700 \mathrm{~K}$ region and to premelting contribution at increasing temperatures.

The assistance of Norikazu Komada with the lower-temperature calorimetric measurements at $\Lambda \mathrm{nn}$ Arbor and with the theoretical calculations, the assistance of Bjørn Lyng Nielsen with the preparation of the Oslo sample and in the highertemperature calorimetric measurements, that of Curator Gunnar Raade of the Mineralogical-Geological Museum of the University of Oslo for the sample of iodyrite (jodargyrite), and that of Professor $\mathrm{Dr}$ J. Nölting, for provision of unpublished experimental heat-capacity values are gratefully acknowledged.

\section{REFERENCES}

I. Mellander, B.-E.; Bowling, J. E.; Baranowski, B. Phisica Scripta 1980, $22,541$.

2. Burley, G. Am. Mineral 1963, 48, 1266.

3. Burley, G. J. Phys. Chem. 1964, 68. 1111.

4. Strock, L. W. Z. Phys. Chem. 1934, 25, 441.

5. Tubandt, C.; Lorenz, E. Z. Phys. Chem. 1914, 87, 513, 543.

6. Perrott, C. M.: Fletcher, N. H. J. Chem. Phys. 1968, 48, 2143. 
7. Perrott, C. M.; Fletcher. N. H. J. Chem. Phys. 1968, 48, 2681

8. Perrott, C. M.; Fletcher, N. H. J. Chem. Phys. 1969, 50, 2770.

9. Perrott, C. M.; Fletcher, N. H. J. Chem. Phis. 1970, 52, 3368

10. Perrott, C. M.; Fletcher, N. H. J. Chem. Phys. 1970, 52, 3373.

11. Jost, W. J. Chom. Phys. 1971, 55, 4680.

12. Lieser, K. H. Z. Phy's. Chem. N.F. (Frankfurt) 1954, 2, 238.

13. Hoshino, S. J. Phys. Soc. Jpn 1957, 12, 315.

14. Jost, W.: Oel. H. J.: Schniedermann. G. Z. Phys. Chem. N.F. (Frankfurt) 1958, 17, 175.

15. Nölting, J. Ber. Bunsenges. Phys. Chem. 1963, 67, 172.

16. Nölting, J.; Rein, D. Z. Phys. Chem. N.F. (Frankfurt) 1969, 66, 150.

17. Nernst, W; Schwers, F. Sizber. kgl. Preuss. Akad. Wiss. 1914, 355; Ann. Physik 1911, $36,395$.

18. Pitzer, K. S. J. Am. Chem. Soc. 1941, 63, 516.

19. Madison, M. R.; LeDuc, H. G.; Coleman, L. B. J. Chem. Phys. 1984, 81, 470 (See also LeDuc, H. G., Coleman, L. B. Solid State Ionics 1981, 5, 469.)

20. Perrott, C. M.; Fletcher, N. H. J. Chem. Phys. 1969, 50, 2344.

21. Grønvold, F.; Westrum. E. F., Jr. J. Chem. Thermodynamics 1986, 18, 381.

22. Okazaki, H.; Takano, A. Z. Naturforsch., A: Phys., Phys. Chem., Kosmophys. 1985, 40A(10), 986.

23. Allen, P. C.; Lazarus, D. Phys. Rev. B 1978, 17, 1913.

24. Fontana, A.; Mariotto, G.; Fontana, M. P. Phys. Rev. B 1980, $21,1102$.

25. Mariotto, G.; Fontana. A.; Cazzanelli, E.; Rocca, F.; Fontana, M. P.; Mazzacurati, V.; Signorelli, G. Phys. Rev. B 1981, 23, 4782.

26. Tallon, J. Phys. Rev. Lett. 1986, 57, 2427.

27. Börjesson, L.; Torell, L. M. Solid State Ionics (in press).

28. Mazzacurati, V.; Ruocco, G.; Signorelli. G.: Cazzanelli, E.; Fontana, A.; Mariotto, G. Phys. Rev. B 1982, 26, 2216.

29. Lawn, B. R. Acta Cryst. 1964, 17, 1341

30. Szabó, G. J. Phys. C: Solid State Phys. 1986, 19, 3775

31. Szabó, G.; Kertèsz, J. J. Phys. C: Solid State Phys. 1986, 19, L273.

32. Henisch, H. K. Crystal Growth in Gels. Pennsylvania State University Press: University Park, PA. 1970.

33. Suri, S. K.; Henisch, I1. K.; Faust, J. W. J. Cryst. Growth 1970, 7, 277.

34. Deslattes, R. D.; Henins, A. Phys. Rev. Lett. 1973, 31, 972.

35. Ersson, N. O. Personal communication.

36. Burley, G. J. Chem. Phys. 1963, 38, 2807.

37. Chateau, H.; de Cugnac, A.; Pouradier, J. Compt. Rend. (Paris) 1964, 258, 1548.

38. Wilman, H. Proc. Phys. Soc. London 1940, 52, 323.

39. Burley, G. J. Phys. Chem. Solids 1964, 25, 629.

40. Berry, C. R. Acta Cryst. 1949, 2, 393.

41. Yvon, K.; Jeitschko, W.; Parthé, E. J. Appl. Crystallography 1977, 10, 73.

42. Cava, R. J.; Reidinger, F.; Wuensch, B. J. J. Solid State Comm. 1977, 24, 411.

43. Westrum, E. F.. Jr.: Furukawa, G. T.; McCullough. J. P. Experimental Thermodynamics, Vol. I. McCullough, J. P.; Scott, D. W.: editors. Butterworth: London. 1968, p. 133.

44. Saito, K.; Atake. T.; Chihara, H. J. Chem. Thermodynamics 1987, 19, 633.

45. Inaba, A. J. Chem. Thermodynamics 1983, 15, 1137.

46. Inaba, A.; Fujii, H.; Chihara, H. To be published.

47. Gronvold, F. Acta Chem. Scand. 1967, 21, 1695.

48. Nölting. J. Personal communication. 1984.

49. Avogadro, A.; Dworkin, A.; Ferloni, P.; Ghenfentein, M.: Magistris, A.: Szwarc, H.; Toscani, S. J. Non-cryst. Solids 1983, 58, 2-3.

50. Helmholz, L. J. Chem. Phys. 1935, 3, 740.

51. Bührer, W.; Nicklow, R. M.; Brüesch, P. Phys. Rev. B 1978, 17, 3362.

52. Komada, N.; Westrum. E. F., Jr. To be published.

53. Singh. D.; Varshni, Y. P. Phys. Rev. B 1981, 24, 4340.

54. Lieser, K. H. Z. Phys. Chem. N.F. (Frankfurt) 1955, 5, 125.

55. Davis, B. L.: Blair, D. N. J. Geophys. Res. 1968, 73, 6019.

56. Fjeldly, T, A.; Hanson, R. C. Phy's. Rev. B 1974, 10, 3569.

57. Weiss, K. Z. Phys. Chem. N.F. (Frankfurt) 1968, 59. 318.

58. Yamada, Y. Dissertation, University of Göttingen, Physical Chemistry Institute. 1958.

59. Börjesson, L. Dissertation, Department of Physics, Chalmers University, Sweden. 1987.

60. Börjesson. L.: Torell. L. M. Phys. Rev. B. 1987, 36, 4915. 
61. Shahi, K.; Weppner, W.; Rabenau, A. Phys. stat. sol. (a) 1986, 93, 171.

62. Shahi, K.; Wagner, J. B., Jr. Phys. Rev. B 1981, $23,6417$.

63. Strock, L. W. Z. phys. Chem. B 1936, 31, 132.

64. Bührer, W.; Hälg. W. Helv. Phys. Acta 1974, 47, 27.

65. Hoshino, S.; Sakuma, T.; Fujii, Y. Solid State Comm. 1977, 22, 763.

66. Boyce, J. B.; Hayes, T. M.; Stutius, W.; Mikkelsen, J. C.. Jr. Phys. Rev. Lett. 1977, 38, 1362.

6?. Beyeler, H. U.; Bruesch, P.; Pietronero, L.; Schneider, W. R.; Strassler, S.; Zeller, H. R. Superionic Conductors, Topics in Current Physics 15. Salamon, M. B.: editor. Springer-Verlag: Berlin. 1979. p. 77.

68. Bellati, M.; Romanese, R. Phil. Trans. Roy. Soc. London 1882, 173, 1169.

69. Mallard, E.; Le Chatelier, H. Bull. Soc. Min. France 1883, 6, 181: Compt. Rend (Paris) 1883. 97.102.

70. Bridgman, P. W. Proc. Am. Acad Arts Sci. 1915, 51, 55.

71. Cohen, E.; Joss, E. J. J. Am. Chem. Soc. 1928, 50, 727.

72. Hennicke, H. Dissertation, IIalle a.d.S. 1938, p. 17

73. Majumdar, A. J. Dissertation, Pennsylvania State University. University Park. 1958, p. 152.

74. Majumdar, A. J.; Roy, R. J. Phys. Chem. 1959, 63, 1858.

75. Rao, K. J.; Rao, C. N. R. J. Mater. Sci. 1966, 1, 23.

76. Berger, C.; Raynaud, R.; Richard, M.; Eyraud, L. Compl. Rend. B (Paris) 1967, 265, 716.

77. Carré, J.; Pham, H.; Rolin, M. Bull. Soc. Chim. France 1969, 2322.

78. Natarajan, M.; Rao, C. N. R. J. Chem. Soc. A. 1970, 3087.

79. Mellander, B.-E.; Baranowski, B.; Lundén, A. Phys. Rev. B 1981, 23, 3770.

80. Quaranta, N. E.; Bazán, J. C. Solid State lonies 1983, 11, 71

81. Jost, W. Diffusion in Solids, Liquids, and Gases. Academic Press: New York. 1960, p. 95.

82. Shapiro, S. M.; Feidinger, F. Physics of Superionic Conductors. Salamon. M. B.: editor. SpringerVerlag: Berlin. Heidelberg. 1979, p. 45.

83. Huberman, B. A.; Martin, R. M. Phys. Rev, B 1976, 13, 1498. 